\title{
Deviant Ryanodine Receptor-Mediated Calcium Release Resets Synaptic Homeostasis in Presymptomatic 3xTg-AD Mice
}

\author{
Shreaya Chakroborty, Ivan Goussakov, Megan B. Miller, and Grace E. Stutzmann \\ Department of Neuroscience, Rosalind Franklin University/The Chicago Medical School, North Chicago, Illinois 60064
}

\begin{abstract}
Presenilin mutations result in exaggerated endoplasmic reticulum (ER) calcium release in cellular and animal models of Alzheimer's disease (AD). In this study, we examined whether dysregulated ER calcium release in young 3xTg-AD neurons alters synaptic transmission and plasticity mechanisms before the onset of histopathology and cognitive deficits. Using electrophysiological recordings and two-photon calcium imaging in young (6-8 weeks old) $3 \mathrm{xTg}$ - $\mathrm{AD}$ and non-transgenic (NonTg) hippocampal slices, we show a marked increase in ryanodine receptor (RyR)-evoked calcium release within synapse-dense regions of CA1 pyramidal neurons. In addition, we uncovered a deviant contribution of presynaptic and postsynaptic ryanodine receptor-sensitive calcium stores to synaptic transmission and plasticity in 3xTg-AD mice that is not present in NonTg mice. As a possible underlying mechanism, the RyR2 isoform was found to be selectively increased more than fivefold in the hippocampus of 3xTg-AD mice relative to the NonTg controls. These novel findings demonstrate that $3 \mathrm{xTg}-\mathrm{AD} \mathrm{CA} 1$ neurons at presymptomatic ages operate under an aberrant, yet seemingly functional, calcium signaling and synaptic transmission system long before $\mathrm{AD}$ histopathology onset. These early signaling alterations may underlie the later synaptic breakdown and cognitive deficits characteristic of later stage $\mathrm{AD}$.
\end{abstract}

\section{Introduction}

Alzheimer's disease $(\mathrm{AD})$ is a progressive neurodegenerative disorder characterized clinically by cognitive impairments and histopathologically by amyloid plaques, neurofibrillary tangles, and synaptic loss. $\mathrm{AD}$ is defined by these late-stage deficits, but identifying early pathogenic mechanisms has primarily been elusive except for increased endoplasmic reticulum (ER) calcium release linked to presenilin (PS) mutations. Dysregulated ER calcium is increasingly implicated as a pathogenic factor in AD (LaFerla, 2002; Mattson and Chan, 2003; Stutzmann, 2007) and is observed across several mutant PS1-expressing systems, mouse models, and human fibroblasts (Ito et al., 1994; Guo et al., 1996; Leissring et al., 1999; Stutzmann et al., 2004, 2006).

There are several mechanisms proposed for the effects of mutant PS on calcium signaling. Bezprozvanny and colleagues suggest that the function of mutant PS as an ER leak channel is impaired, resulting in overfilled ER calcium stores ( $\mathrm{Tu}$ et al., 2006; Nelson et al., 2007). Alternatively, mutant PS1 may increase the $\mathrm{IP}_{3}$ receptor $\left(\mathrm{IP}_{3} \mathrm{R}\right)$ channel open probability at normally threshold $\mathrm{IP}_{3}$ concentrations, thereby increasing calcium release (Cheung et al., 2008). We and others propose that PS1-mediated calcium dysregulation is primarily mediated through ryanodine receptor (RyR) upregulation (Smith et al., 2005; Stutzmann et al.,

\footnotetext{
Received April 30, 2009; revised June 2, 2009; accepted June 9, 2009.

We thank Dr. Thanos Tzounopoulos for assistance and guidance with the plasticity experiments.

Correspondence should be addressed to Dr. Grace E. Stutzmann, Department of Neuroscience, Rosalind Franklin University/The Chicago Medical School, 3333 Green Bay Road, North Chicago, IL 60064. E-mail: grace.stutzmann@rosalindfranklin.edu.

D0I:10.1523/JNEUROSCI.2047-09.2009

Copyright $\odot 2009$ Society for Neuroscience $\quad$ 0270-6474/09/299458-13\$15.00/0
}

2006, 2007). Consistent with this, the PS1 N-terminal region binds to and potentiates RyR activity (Rybalchenko et al., 2008), and mutant PS1 may represent a gain of function. Regardless of mechanism, it is evident that mutant PS increases ER calcium release long before histopathology onset.

ER calcium signaling has a central role in neuronal physiology, synaptic transmission, and plasticity (Berridge, 1998; Verkhratsky, 2002; M. K. Park et al., 2008). Presynaptically, calcium is fundamental in neurotransmitter release and paired pulse facilitation (PPF) (Bouchard et al., 2003) (but see Carter et al., 2002). Postsynaptically, ER calcium integrates with synaptically evoked responses (Ross et al., 2005; Watanabe et al., 2006), modulates membrane excitability and channel function (Stutzmann et al., 2003; Hagenston et al., 2008), and initiates gene transcription (Mellström and Naranjo, 2001; Watanabe et al., 2006). Long-term synaptic plasticity is also modulated by ER calcium signaling. Blocking ER calcium obstructs longterm potentiation (LTP) expression, whereas recruitment of ER calcium can reverse polarity from LTP to long-term depression (LTD) (Obenaus et al., 1989; Nishiyama et al., 2000; C. S. Park et al., 2008).

Previous studies in 3xTg-AD and other AD mouse models have examined hippocampal plasticity and found no functional alterations until the onset of $\beta$-amyloid $(\mathrm{A} \beta)$ deposition (Oddo et al., 2003; Rowan et al., 2003). In addition, numerous studies have implicated various $\mathrm{A} \beta$ species in synaptic impairments (Townsend et al., 2006; Selkoe, 2008; Shankar et al., 2008). However, given the early and dramatic calcium dysregulation in the $3 \mathrm{xTg}-\mathrm{AD}$ mice and considering the critical role of calcium in synaptic function, we further investigated 
the impact of aberrant RyR-calcium release on synaptic activity in young $3 \mathrm{xTg}-\mathrm{AD}$ mice before $\mathrm{A} \beta$ deposition. Here, we uncover marked differences in the utilization of RyR-calcium stores that affect both basal synaptic transmission and plasticity in the $3 \mathrm{xTg}-\mathrm{AD}$ mice.

\section{Materials and Methods}

\section{Transgenic mice}

Six- to 8-week-old triple transgenic (3xTg-AD) mice and age-matched non-transgenic (NonTg) controls were used in all experiments. The derivation and characterization of the $3 \mathrm{xTg}-\mathrm{AD}$ (APPswe, $\mathrm{Tau}_{\mathrm{P} 301 \mathrm{~L}}$, and $\mathrm{PS}_{\mathrm{M} 146 \mathrm{~V}} \mathrm{KI}$ ) mice have been described previously (Oddo et al., 2003). NonTg control mice were of the same background strain (129/C57BL/6) as the $3 \times \mathrm{Tg}-\mathrm{AD}$ mice.

\section{Hippocampal slice preparation}

Transverse hippocampal slices were prepared in observance with protocols approved by the Rosalind Franklin University Institutional Animal Care and Use Committee. Briefly, mice were deeply anesthetized with halothane in an enclosed chamber and decapitated. The brains were rapidly extracted, and transverse hippocampal slices $(400 \mu \mathrm{m}$ for field potential recordings and $300 \mu \mathrm{m}$ for patch-clamp/imaging experiments) were cut with a Vibroslice oscillating microslicer (Campden Instruments) into ice-cold oxygenated artificial CSF (aCSF) with the following composition (in mM): $125 \mathrm{NaCl}, 2.5 \mathrm{KCl}, 1.25 \mathrm{KH}_{2} \mathrm{PO}_{4}, 10$ dextrose, 25 $\mathrm{NaHCO}_{3}, 2 \mathrm{CaCl}_{2}$, and 1.2 $\mathrm{MgSO}_{4}, \mathrm{pH} 7.4$ (Stutzmann et al., 2003). Intact slices were placed in a holding chamber containing aCSF at room temperature $\left(27^{\circ} \mathrm{C}\right)$ and oxygenated with $95 \% \mathrm{O}_{2}-5 \% \mathrm{CO}_{2}$. For recording extracellular field potentials, slices were transferred to an interface chamber (Harvard Apparatus) and perfused with oxygenated aCSF (1.5 $\mathrm{ml} / \mathrm{min})$ at room temperature $\left(27^{\circ} \mathrm{C}\right)$ and covered with a continuous flow of humidified gas $\left(95 \% \mathrm{O}_{2}-5 \% \mathrm{CO}_{2}\right)$.

\section{Field potential recordings and drug treatment protocol}

Data were acquired at $10 \mathrm{kHz}$ using pClamp 9.2 software with an Axoclamp 2B amplifier and a DigiData 1322 board for digitization (Molecular Devices). Field EPSP (fEPSPs) were recorded in the stratum radiatum of the CA1 subfield of the hippocampus at room temperature $\left(27^{\circ} \mathrm{C}\right)$ using recording microelectrodes $(2-6 \mathrm{M} \Omega$ ) filled with standard aCSF. Microelectrodes were pulled from glass capillaries (World Precision Instruments) on a P-2000 pipette puller (Sutter Instruments). Synaptic responses were evoked by stimulation of the Schaffer collateral/commissural pathway with a bipolar stimulating electrode. Baseline fEPSPs were evoked at $50 \%$ of the maximum fEPSP at $0.05 \mathrm{~Hz}$ for $20 \mathrm{~min}$ before and for $1 \mathrm{~h}$ after induction of LTP. LTP was induced at baseline intensity using high-frequency stimulation consisting of two trains of $100 \mathrm{~Hz}$ at a $10 \mathrm{~s}$ interval. Input/output (I/O) curves were generated using stimulus intensities from 0 to $225 \mu \mathrm{A}$ in increments of $25 \mu \mathrm{A}$. PPF was assessed using an interstimulus interval of $50 \mathrm{~ms}$. Ten successive traces were recorded for PPF at $0.05 \mathrm{~Hz}$. In protocols with drug treatment, a $20 \mathrm{~min}$ baseline at $0.05 \mathrm{~Hz}$ was recorded in aCSF, after which dantrolene (RyR antagonist, $10 \mu \mathrm{M}$; Tocris Bioscience), caffeine (RyR agonist, $5 \mathrm{~mm}$; Sigma-Aldrich), or DPCPX (8-cyclopentyl-1,3-dipropylxanthine) [adenosine $A_{1}$ receptor $\left(A_{1} R\right)$ antagonist, $1 \mu \mathrm{M}$; Sigma-Aldrich] in aCSF was perfused continuously over the slice. The same stimulus was used to record a $20 \mathrm{~min}$ baseline in the drug, after which LTP was induced, followed by a $1 \mathrm{~h}$ baseline in the drug. Apamin (SK channel antagonist, 1 $\mu \mathrm{M}$; Sigma-Aldrich) was used in the I/O protocol.

Picrotoxin $\left(\mathrm{GABA}_{\mathrm{A}}\right.$ receptor antagonist, $50 \mu \mathrm{M}$; Sigma-Aldrich) had been tested in initial field potential experiments in both NonTg and $3 \mathrm{xTg}-\mathrm{AD}$ slices but was not used in the experiments presented in this study. We analyzed data with and without picrotoxin and found no significant differences between them $\left(\mathrm{I} / \mathrm{O}, t_{(1,10)}=0.54, p>0.05\right.$; PPF, $t_{(1,10)}=0.17, p>0.05$; LTP, $t_{(1,10)}=1.47, p>0.05 ; n=7$ for aCSF, $n=$ 5 for picrotoxin). We feel this reflects the anatomical characteristics of the medial and distal portions of the stratum radiatum of the CA1 subfield, in which we placed our recording electrodes, which receive sparse GABAergic inputs (Megías et al., 2001). For clarity, the data shown include only non-picrotoxin conditions.
Patch-clamp recordings and two-photon calcium imaging

Whole-cell recordings and solutions. In a separate set of experiments, visualized whole-cell patch-clamp recordings were performed using infrared-differential interference contrast optics. Slices were placed in a perfusion chamber mounted on a movable stage assembly on a fixed upright microscope (BX51WI; Olympus). Patch pipettes (4-5 M $\Omega$ ) were pulled from borosilicate glass capillaries (World Precision Instruments) and filled with the following (in mM): $135 \mathrm{~K}$-methylsulfonate, $10 \mathrm{HEPES}$, 10 Na-phosphocreatine, $2 \mathrm{MgCl}_{2}, 4 \mathrm{NaATP}$, and $0.4 \mathrm{NaGTP}, \mathrm{pH}$ adjusted to 7.3-7.4 with $\mathrm{KOH}$ (as well as $50 \mu \mathrm{M}$ fura-2) (Invitrogen). Recordings were performed at room temperature $\left(27^{\circ} \mathrm{C}\right)$. In these experiments, TTX was not included in the bath solution because previous experiments showed no differences in the spontaneous synaptic events in pyramidal neurons from NonTg or 3xTg-AD mice, with or without TTX (frequency, $p=0.34$; amplitude, $p=0.65$, respectively). This likely reflects the lack of spontaneous action potentials in the slice preparation. Signals were acquired at $1 \mathrm{kHz}$ using a MultiClamp 700B amplifier (Molecular Devices) and analyzed using pClamp 10.0 software. Access resistance was continually monitored, and cells were used for recording only if the access resistance was maintained at $<7 \mathrm{M} \Omega$.

Calcium imaging. Imaging of fluorescent calcium signals was performed using a custom built two-photon microscope. In brief, excitation was provided by trains $(80 \mathrm{MHz})$ of ultra-short ( $<100 \mathrm{fs})$ pulses at 780 $\mathrm{nm}$ from a titanium/sapphire laser (Mai Tai Broadband; Spectra Physics) pumped by a solid-state laser (Millenia 5X; Spectra Physics). The laser beam was scanned by a resonant galvanometer (General Scanning Lumonics) allowing rapid $(7.9 \mathrm{kHz})$ bidirectional scanning in the $x$-axis and by a conventional linear galvanometer in the $y$-axis, to provide a framescan rate of 30 frames/s. The scanned beam was focused onto the specimen through a $40 \times$ water-immersion objective (numerical aperture 0.8 ). Emitted fluorescence light was collected through the same objective and, after passing through a short-pass filter $(<650 \mathrm{~nm})$ to block laser light, was detected by a wide-field photomultiplier (Electron Tubes) mounted on the photo-port of the trinocular head. Data were obtained using fura-2 as the calcium ion indicator. Two-photon excitation of fura-2 at $780 \mathrm{~nm}$ is equivalent to conventional (one-photon) excitation at $380 \mathrm{~nm}$, in that it shows a decrease in fluorescence on binding calcium ions rather than an increase as with most other indicators. The basal fluorescence is thus high, facilitating identification of cellular structures and measurement of small calcium increases over the resting level. Second, fura-2 shows a large dynamic range, with the fluorescence intensity changing $>10$-fold from resting to saturating $\left[\mathrm{Ca}^{2+}\right]$. Fura- 2 was chosen for this study based on these reasons and after assays of multiple fluorescent $\mathrm{Ca}^{2+}$ indicators were performed examining a range of $K_{\mathrm{d}}$ values $(50 \mu \mathrm{M}$ to $140 \mathrm{nM})$. For clarity of presentation, images and traces of fura-2 fluorescence were expressed as a pseudo-ratio $F_{0} / \Delta F$ (where $F_{0}$ is resting fluorescence and $\Delta F$ is the decrease of fluorescence on stimulation), so that increases in $\left[\mathrm{Ca}^{2+}\right]$ correspond to increasing ratios, and fura- 2 produced the highest fluorescent signal with little saturation or phototoxicity.

\section{RNA extraction and reverse transcription}

Total mouse hippocampal RNA was extracted and purified from 20-40 mg samples (wet weight) dissected from young (6-8 weeks old) 3xTg-AD and NonTg animals using TRI Reagent and the corresponding protocol (Invitrogen). RNA was constituted in sterile, nuclease-free water, and sample concentrations were determined spectrophotometrically at $\mathrm{DO}_{260 \mathrm{~nm}}$. After DNase treatment of $1 \mu \mathrm{g}$ of total RNA (DNAfree kit; Ambion), dNTP and random primers were used for cDNA synthesis using the High Capacity Reverse Transcription kit (Applied Biosystems) and associated protocol.

\section{Quantitative real-time PCR}

One microliter of the resulting cDNA products was evaluated using realtime PCR. Target genes were amplified and evaluated using the 7500 RT PCR System and SYBR green detection (Applied Biosystems). Cycling parameters were as follows: $2 \mathrm{~min}$ at $50^{\circ} \mathrm{C}, 10 \mathrm{~min}$ at $95^{\circ} \mathrm{C}$, and then 40 cycles at $95^{\circ} \mathrm{C}$ for $15 \mathrm{~s}$, followed by $60^{\circ} \mathrm{C}$ for $60 \mathrm{~s}$. A dissociation phase was added to the end of each cycle to determine product purity. Oligonucle- 
otide primers were synthesized by Invitrogen for target gene amplification. Cyclophilin A was used as an endogenous control (housekeeping) gene. Primer sequences are as follows: RyR1: forward (F), 5'-TCTTCCCTGCTGGAGACTGT-3'; reverse (R), 5'-GTGGAGAAGGCACTTGAGG-3'; RyR2: $\mathrm{F}, \quad 5^{\prime}-$ TCAAACCACGAACACATTGAGG-3'; R, 5' AGGCGGTAAAACATGATGTCAG-3'; RyR3: F, 5'-CTGGCCATCATTCAAGGTCT-3'; R, 5'-GTCTCCATGTCTTCCCGTA-3'; CycloA: F, 5'-GGCCGATGACGAGCCC-3'; R, 5' TGTCTTTGGAACTTTGTCTGCAAAT-3' . Primer specificities were validated by the presence of a single amplicon for each primer set at the predicted sizes $(95,125$, and 83 bp for RyR1, RyR2, and RyR3, respectively) after agarose gel electrophoresis of PCR products and ethidium bromide detection. Product purity was supported by the presence of a single peak present on dissociation/melt curves for each primer set. Each sample was evaluated in triplicate. Amplification data were analyzed using the comparative cycle threshold $\left(\Delta \Delta \mathrm{C}_{\mathrm{t}}\right)$ method after normalization to Cyclophilin A and are represented as mean \pm SEM relative mRNA expression levels. A two-tailed $t$ test was used to determine statistical significance.

Data analysis and statistics

For LTP recordings, maximum fEPSP slopes were measured offline using pClamp 9.2 software and analyzed using Origin Pro8 and Microsoft Excel software. The maximum fEPSP slopes were expressed as a percentage of the average slope from the $20 \mathrm{~min}$ baseline recordings. PPF fEPSP amplitudes were measured offline using the same software and expressed as a ratio of second fEPSP amplitude over first fEPSP amplitude. For I/O curves, the first $5 \mathrm{~ms}$ of the fEPSP slopes were measured offline using the same software. Data are expressed as mean \pm SEM and assessed for significance using the Student's two-tailed $t$ test or paired $t$ test, or one-way ANOVA with Scheffé's post hoc analysis, where $n$ denotes the number of slices examined unless otherwise stated. For calcium imaging and intracellular recordings, relative changes in maximal intracellular calcium were calculated after background subtraction as a pseudo-ratio based on changes in fura-2 fluorescence intensity levels relative to baseline (Stutzmann et al., 2003, 2004). Statistical differences in evoked calcium responses between the NonTg and 3xTg-AD neurons were determined by unpaired $t$ tests. For determining significance in cumulative probability histograms, nonparametric Kolmogorov-Smirnov (K-S) tests were performed using Origin Pro8 software.

\section{Results}

Enhanced RyR-evoked calcium release within 3xTg-AD CA1 neuronal compartments: effects on spontaneous postsynaptic potentials

Hippocampal CA1 pyramidal neurons from 6- to 8-week-old mice were visually

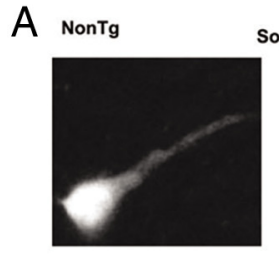

Soma

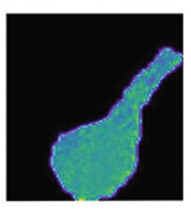

C $3 \times T g-A D$
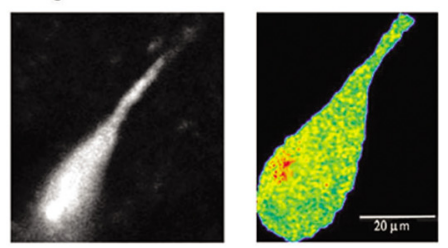

B

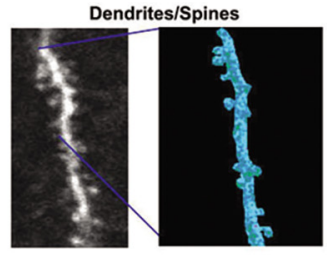

D
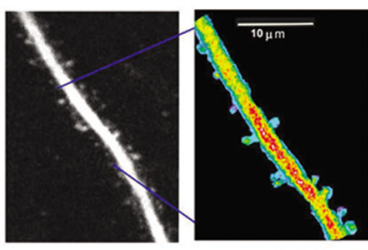

$\begin{array}{lll}0 & 0.1 & 0.2\end{array}$
$E$
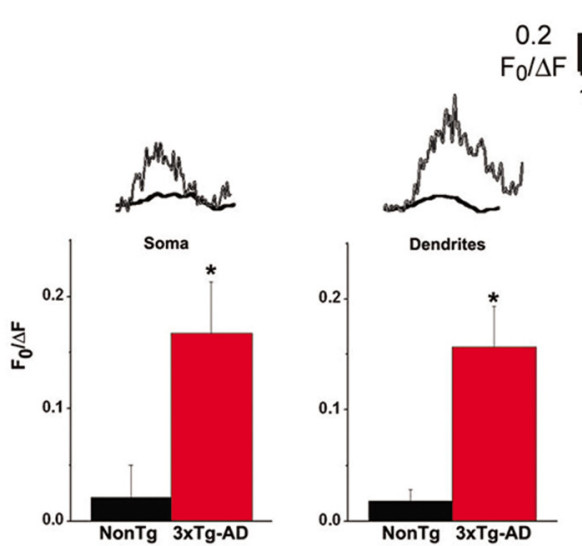

$\mathrm{F}$

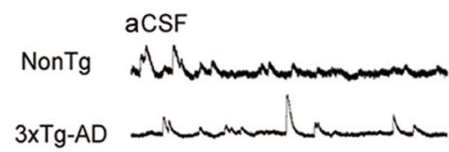

\section{Caffeine}
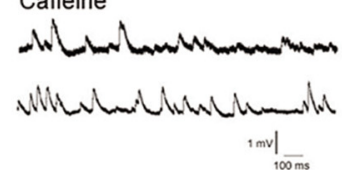

G
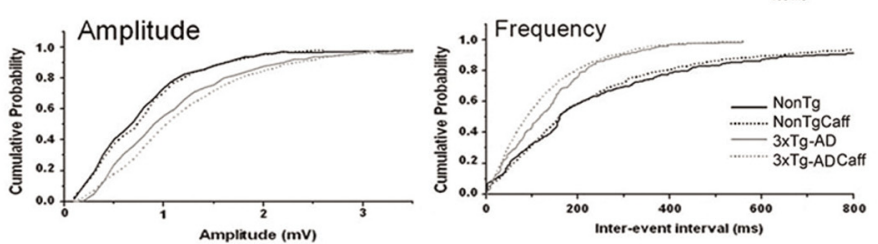

$\mathrm{H}$
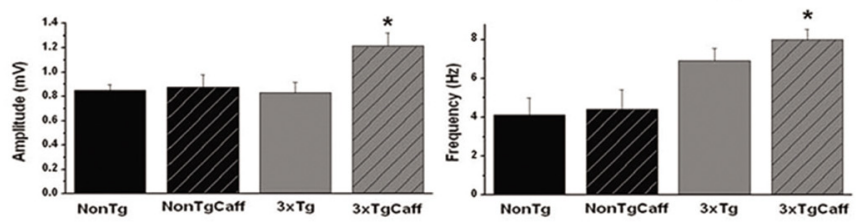

Figure 1. Increased RyR-evoked $\mathrm{Ca}^{2+}$ release in CA1 hippocampal neurons from 3xTg-AD mice. $A$, Left, Baseline tw0photon $\mathrm{Ca}^{2+}$ image of a representative CA1 pyramidal neuron from a NonTg mouse. Right, Pseudocolored image of $\mathrm{Ca}^{2+}$ signals evoked by $5 \mathrm{~mm}$ caffeine. Colors correspond to relative $\mathrm{Ca}^{2+}$ changes indicated by the color scale below. $\boldsymbol{B}$, Left, Two-photon image of a segment of dendrite and spines from a NonTg CA1 pyramidal neuron at rest. Right, Pseudocolored image of same dendritic region showing relative $\mathrm{Ca}^{2+}$ changes after caffeine application. $\boldsymbol{C}$, Same as in $\boldsymbol{A}$ but from a 3xTg-AD neuron. $\boldsymbol{D}$, Same as in $\boldsymbol{B}$ but from a 3xTg-AD neuron. $\boldsymbol{E}$, Bar graphs comparing averaged maximal $\mathrm{Ca}^{2+}$ changes in the soma (left), dendrite (middle), and spine heads (right) between NonTg and 3xTg-AD CA1 pyramidal neurons. ${ }^{*} p<$ 0.05 , significantly different from NonTg within anatomical subregions,. $F$, Representative traces of spontaneous postsynaptic potentials recorded from CA1 pyramidal neurons from NonTg (top) and 3xTg-AD mice (bottom) in control aCSF (left) and $5 \mathrm{~mm}$ caffeine (right). $G$, Cumulative probability histograms demonstrating that caffeine increases the amplitude (left) and frequency (right) of spontaneous potentials only in the 3xTg-AD mice ( $K-S$ test, $p<0.05$ ). $\boldsymbol{H}$, Bar graphs show averaged amplitude (left) and frequency (right) values of spontaneous postsynaptic potentials for NonTg (black) and 3xTg-AD (gray) neurons in control aCSF (solid) or $5 \mathrm{~mm}$ caffeine (stripes). Caffeine significantly increased both amplitude and frequency measurements in the $3 \mathrm{xTg}-\mathrm{AD}$ neurons relative to all NonTg conditions, ${ }^{*} p<0.05$. 
selected based on morphology and confirmed electrophysiologically (Shelbourne et al., 2007). Once whole-cell configuration was established, the calcium indicator dye fura-2 diffused throughout the cell for $10 \mathrm{~min}$ before imaging. Baseline fluorescence was not different between NonTg and 3xTg-AD neurons at rest $(p>$ 0.05 ; data not shown). Caffeine ( $5 \mathrm{mM})$ was bath applied for 1 min, and maximal relative calcium changes from baseline were measured either in the soma/proximal dendrite regions or distal dendrites/spines in the CA1 stratum radiatum subfield, followed by a 10 min washout period (Fig. 1). This relatively low caffeine dose was chosen for this study based on its threshold calcium response in the NonTg mice and minimal epileptiform activity via disinhibition of the adenosine $A_{1}$ receptor in field potential recordings. In the soma/proximal dendrite regions, RyR activation evoked a significantly greater calcium response in the $3 x T$-AD neurons $\left(F_{0} / \Delta F=0.17 \pm 0.05, n=5\right)$ compared with the NonTg mice $\left(F_{0} / \Delta F=0.02 \pm 0.03, n=5 ; t_{(1,9)}=2.7 ; p<\right.$ $0.05)$. In the distal dendrites, there was a significantly greater caffeine-evoked calcium response from $3 \mathrm{xTg}-\mathrm{AD}$ mice $\left(F_{0} / \Delta F=\right.$ $0.16 \pm 0.04, n=12)$ relative to $\operatorname{NonTg}\left(F_{0} / \Delta F=0.018 \pm 0.01\right.$, $\left.n=13 ; t_{(1,24)}=0.11 \pm 0.03\right)$, and, in spine heads, there was a significant 12 -fold increase in the RyR-calcium response from 3xTg-AD mice $\left(F_{0} / \Delta F=0.18 \pm 0.02, n=98\right)$ relative to $\mathrm{NonTg}$ $\left(F_{0} / \Delta F=0.015 \pm 0.01, n=25 ; t_{(1,122)}=2.7 ; p<0.05\right)$.

With the concurrent patch-clamp recordings, spontaneous postsynaptic potentials were recorded for a period of 30-60 s in both control aCSF and $5 \mathrm{~mm}$ caffeine for NonTg and 3xTg-AD neurons ( $n=4$ in each condition), and their amplitude and frequency characteristics were analyzed using MiniAnalysis software (version 6.0.9; Synaptosoft). As shown in Figure 1, F and $G$, cumulative probability histograms of event amplitudes demonstrate that caffeine significantly increases the amplitude (rightward shift) of spontaneous potentials only in the 3xTg-AD neurons relative to NonTg responses in aCSF and caffeine and $3 \times \mathrm{xTg}-\mathrm{AD}$ responses in aCSF (K-S test, $p<0.05)$. Similarly, for analysis of interevent intervals, caffeine significantly increased the frequency of event responses (leftward shift) for the $3 \times \mathrm{Tg}-\mathrm{AD}$ neurons in caffeine relative to NonTg and 3xTg-AD neurons in aCSF (K-S test, $p<0.05)$. Notably, baseline 3xTg-AD responses in aCSF were also shifted leftward relative to NonTg responses in either aCSF or caffeine (K-S test, $p<0.05$ ). Averaged event amplitude and frequency values are shown in Figure $1 \mathrm{H}$, and, in each bar graph, significant increases are demonstrated only in the 3xTg-AD/ caffeine conditions relative to NonTg values (amplitude: one-way ANOVA, $F_{(3,15)}=3.9, p<0.05$, Scheffe's post hoc analysis, $p<0.05$ for 3xTg-AD/caffeine vs 3xTg-AD/aCSF, NonTg/aCSF, and NonTg/ caffeine; frequency: one-way ANOVA, $F_{(3,15)}=5.4, p<0.05$, Scheffé's post hoc analysis, $p<0.05$ for 3xTg-AD/ caffeine vs NonTg/ aCSF and NonTg/caffeine). This indicates that RyR activation increases the average spontaneous postsynaptic potential amplitude, generally considered a postsynaptic measure, in the 3xTg-AD neurons but has no significant effects in NonTg neurons. In addition, baseline event amplitudes are not different between NonTg and 3xTg-AD mice in control aCSF. A similar pattern exists for their frequency, which is generally considered a measure of presynaptic activity and vesicle release. Here, RyR activation increases frequency in the $3 \mathrm{xTg}-\mathrm{AD}$ neurons relative to NonTg neurons (either in aCSF or caffeine) but not in relation to $3 \mathrm{xTg}-\mathrm{AD}$ neurons in aCSF.

RyR2 mRNA levels are upregulated in young 3xTg-AD mice To elucidate a possible mechanism for aberrant RyR-mediated ER calcium utilization in 3xTg-AD mice, we compared mRNA
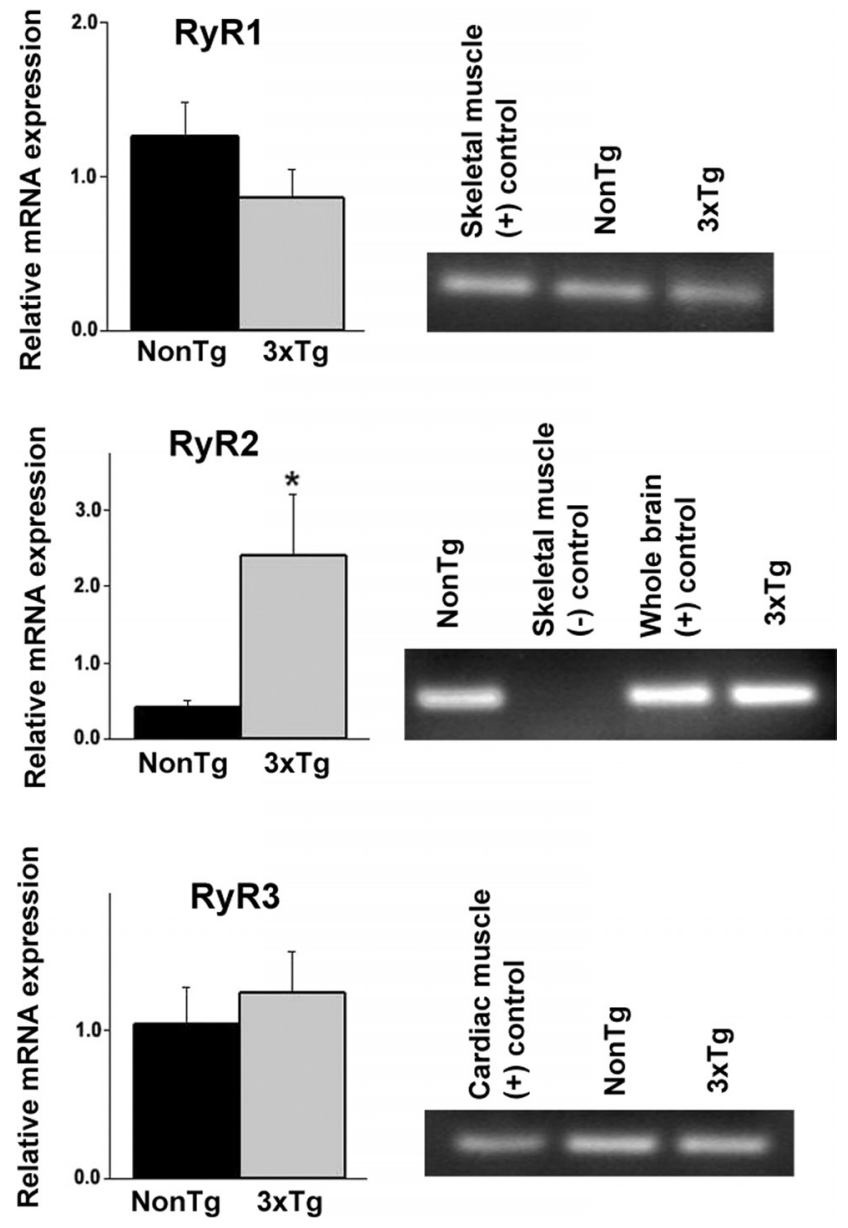

Figure 2. Upregulation of the RyR2 isoform in 3xTg-AD hippocampus. Bar graphs show relative mRNA expression levels of RyR1 (top), RyR2 (middle), and RyR3 (bottom) isoforms from the hippocampus of NonTg (black) and 3xTg-AD (gray) mice. To the right of each graph are the $P C R$ products detected on an agarose gel along with relevant positive and negative controls for each RyR isoform. mRNA levels are relative to control Cyclophilin A levels. ${ }^{*} p<0.05$, significantly different from NonTg levels. Error bars represent \pm SEM.

expression levels of the three RyR isoforms between NonTg and $3 \times$ Tg-AD mice using quantitative reverse transcription-PCR (Fig. 2). The RyR mRNA levels from NonTg and 3xTg-AD mice were normalized to expression levels of Cyclophilin A. There were no differences in RyR1 $\left(n=3, t_{(1,2)}=1.45 ; p>0.05\right)$ or RyR3 expression levels $\left(n=5, t_{(1,4)}=0.67 ; p>0.05\right)$ between NonTg and 3xTg-AD mice. However, RyR2 mRNA expression levels were significantly increased in the hippocampus of $3 \times \mathrm{Tg}-\mathrm{AD}$ mice relative to the NonTg controls $\left(n=5, t_{(1,5)}=3.53\right.$; $p<0.05)$. Therefore, RyR2 upregulation may underlie the exaggerated RyR-mediated ER calcium release and altered synaptic transmission properties in young $3 \mathrm{xTg}-\mathrm{AD}$ mice.

\section{Aberrant contribution of RyR-evoked calcium to synaptic transmission in $3 \times \mathrm{Tg}-\mathrm{AD}$ neurons}

Extracellular field potential recordings were used to study synaptic transmission in the hippocampal CA1 subfield from NonTg and $3 \times \mathrm{xTg}-\mathrm{AD}$ mice. In control aCSF, there were no apparent differences in basal synaptic transmission between NonTg $(n=$ $15)$ and $3 \times \operatorname{Tg}-\mathrm{AD}(n=26)$ mice as determined by the first $5 \mathrm{~ms}$ of the slope of the I/O functions $\left(t_{(1,39)}=0.28 ; p>0.05\right)$ (Fig. $3 A$ ). However, during RyR blockade with $10 \mu \mathrm{M}$ dantrolene, very different patterns of synaptic activity emerged (Fig. $4 A-C$ ). Dan- 
trolene treatment had little effect on basal synaptic transmission in NonTg mice $\left(n=5 ; t_{(1,4)}=1.92 ; p>0.05\right)$, whereas in the $3 \mathrm{xTg}$-AD mice, blocking the RyR resulted in a significantly greater $\mathrm{I} / \mathrm{O}$ function $\left(n=9 ; t_{(1,8)}=6.17 ; p<0.05\right)$. These findings are consistent with RyR-evoked calcium release activating postsynaptic calcium-activated $\mathrm{K}^{+}$channels, likely the SK channels, which mediate the medium afterhyperpolarization and suppress membrane excitability (Stutzmann et al., 2006; Brennan et al., 2008). To assess the role of SK channels in synaptic transmission, we compared the I/O function after blocking these channels with 1 $\mu \mathrm{M}$ apamin (Fig. $4 D, E$ ). In parallel with the effects of dantrolene, apamin had no effect in NonTg mice $\left(n=3 ; t_{(1,2)}=0.5\right.$; $p>0.05)$ yet significantly increased the $\mathrm{I} / \mathrm{O}$ function in $3 \times \mathrm{Tg}-\mathrm{AD}$ mice at higher stimulus intensities $\left(n=4 ; t_{(1,3)}=5.84\right.$; $p<0.05)$. Plotting presynaptic fiber volley (FV) amplitude with postsynaptic fEPSP slopes suggest that neither dantrolene nor apamin altered the properties of presynaptic fibers in NonTg or in $3 \mathrm{xTg}-\mathrm{AD}$ mice (one-way ANOVA, $F_{(1,17)}=1.62$; $p>0.05)$ (data not shown).

\section{Short- and long-term plasticity are differentially modulated by RyR-evoked calcium release in 3xTg-AD neurons}

Presynaptic short-term plasticity was measured by PPF, a form of calcium-dependent plasticity and an indicator of neurotransmitter release probability. In control aCSF (Fig. 3B), PPF was similar between NonTg $(n=21)$ and $3 \times \operatorname{Tg}-\mathrm{AD}(n=33)$ mice, yet distinctions arise between the mouse strains when manipulating RyR-sensitive calcium stores (Fig. 4G-I). Although dantrolene treatment had no observable effects in NonTg mice $(n=5)$, it significantly increased PPF in 3xTg-AD mice ( $n=9$, PPF; one-way ANOVA, $F_{(3,13)}=16.68 ; p<0.05$, Scheffé's post hoc analysis, $p<0.05$ for $3 \times \mathrm{Tg}-\mathrm{AD} /$ dantrolene vs $3 \mathrm{xTg}-\mathrm{AD} / \mathrm{aCSF}$, NonTg/aCSF, and NonTg/dantrolene). This suggests that presynaptic RyRsensitive calcium stores are functionally active and contribute to the readily releasable pool of neurotransmitter vesicles in the $3 \mathrm{xTg}-\mathrm{AD}$ mice but less so in the NonTg mice.

LTP was measured by normalizing the posttetanus fEPSP slope to the pretetanus fEPSP slope values. At 6-8 weeks of age, LTP appeared similar between the two strains of mice $\left[t_{(1,11)}=\right.$ $0.31 ; p>0.05 ; 78.26 \pm 2.0 \%$ over baseline for NonTg mice $(n=$ $7)$ and $80.66 \pm 2.3 \%$ over baseline for $3 \times \mathrm{Tg}-\mathrm{AD}$ mice $(n=6)]$ (Fig. $3 C$ ). It is well established that ER calcium stores are involved in LTP mechanisms. When both baseline and posttetanic responses are measured in the presence of a RyR blocker, LTP is essentially abolished (Obenaus et al., 1989). However, this approach does not take into account drug treatment effects on baseline responses. In this study, we performed a more extensive three-step protocol by recording baseline responses in control aCSF, followed by a new baseline recording in $10 \mu \mathrm{M}$ dantrolene, and then administering the tetanus and measuring potentiation
B

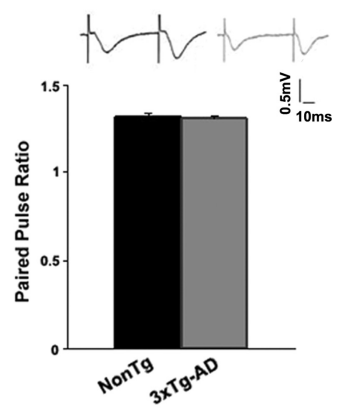

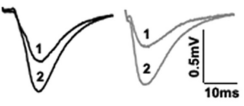

$\rightarrow-3 \times T g \cdot A D$

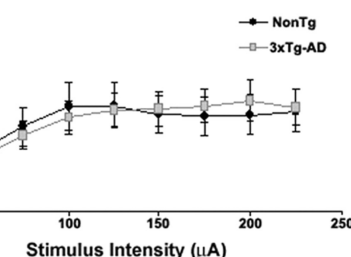

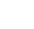

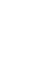

(1)

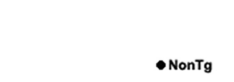

$\square 3 \times T g-A D$

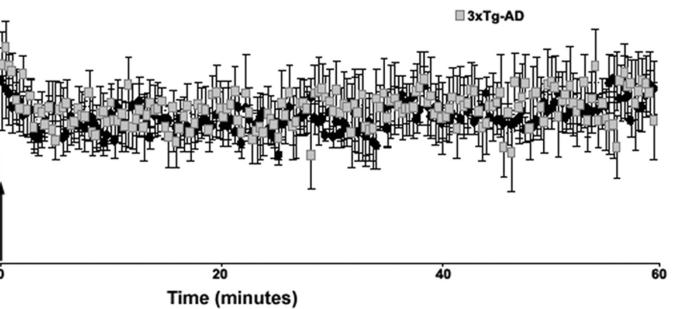

Time (minutes)

Figure 3. Basal synaptic transmission properties of CA3-CA1 Schaffer collaterals recorded from 6- to 8-week-old NonTg and $3 \times \mathrm{XTg}-\mathrm{AD}$ mice. $A$, Top, Representative I/0 traces show changes in fEPSP amplitude with increasing stimulus intensity for NonTg (black) and 3xTg-AD (gray) mice. Bottom, I/O function shows changes in fEPSP slope with increasing stimulus (black; $n=7$ ) and 3xTg-AD (gray; $n=6)$ mice. Bottom raph shows averaged time course of LTP. Baseline fEPSPs were recorded for $20 \mathrm{~min}$ at $0.05 \mathrm{~Hz}$ before and for $60 \mathrm{~min}$ at 0.05 $\mathrm{Hz}$ after induction of LTP. The arrow indicates the time of tetanus (2 trains at $100 \mathrm{~Hz}, 10 \mathrm{~s}$ apart). Error bars represent \pm SEM, and $n$ denotes number of slices.

in dantrolene. This allows comparison of LTP expression against both a control baseline and a drug treatment baseline. With this approach, striking differences in RyR-evoked calcium utilization were observed between NonTg and 3xTg-AD mice (Fig. 5). In NonTg mice $(n=7)$, there was no change in the baseline fEPSP slope after treatment with dantrolene $(5.84 \pm 1.7 \%$ over aCSF baseline; $\left.t_{(1,6)}=0.91 ; p>0.05\right)$, although LTP was reduced when compared with its control aCSF baseline $(32.62 \pm 2.3 \%$ over baseline). In $3 x T g-A D$ mice $(n=5)$, there was a significant decrease in baseline fEPSP slope after dantrolene application $\left(34.85 \pm 2.3 \%\right.$ below aCSF baseline; $\left.t_{(1,4)}=12.22 ; p<0.05\right)$ and modest LTD when compared with control aCSF baseline (17.07 $\pm 1.2 \%$ below baseline). Nevertheless, when compared with baseline in dantrolene, LTP was essentially abolished in both NonTg $(25.29 \pm 1.4 \%)$ and 3xTg-AD (7.02 $\pm 1.9 \%)$ mice, in accordance with previous studies (Obenaus et al., 1989). To monitor long-term dantrolene effects on baseline responses in NonTg and 3xTg-AD mice, we applied $10 \mu \mathrm{M}$ dantrolene for 60 min (LTP protocol duration) and measured baseline synaptic responses at $0.05 \mathrm{~Hz}$ (supplemental Fig. $2 A, B$, available at www. jneurosci.org as supplemental material). We demonstrate here that long-term dantrolene exposure generates a stable response over time in both the NonTg $(2.77 \pm 1.0 \%$ over aCSF baseline; $\left.t_{(1,4)}=1.2 ; p>0.05\right)$ and $3 \mathrm{xTg}-\mathrm{AD}(38.36 \pm 1.3 \%$ below aCSF baseline; $\left.t_{(1,3)}=9.22 ; p<0.05\right)$ mice. Therefore, the differential responses in LTP expression are not attributable to shifting baseline values. 
A
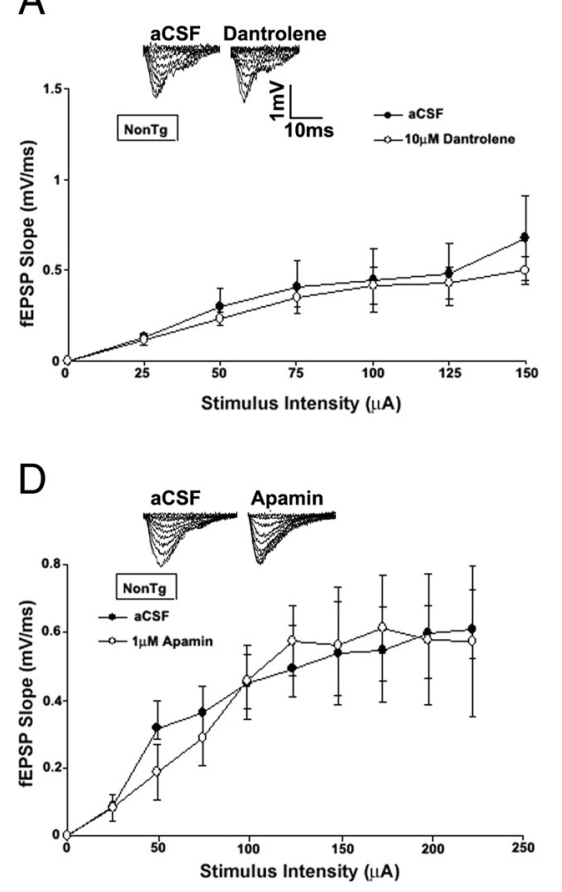

G

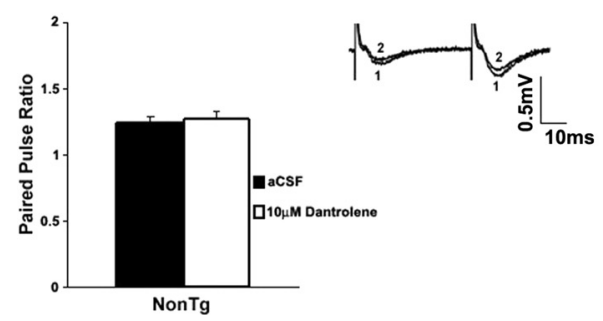

B

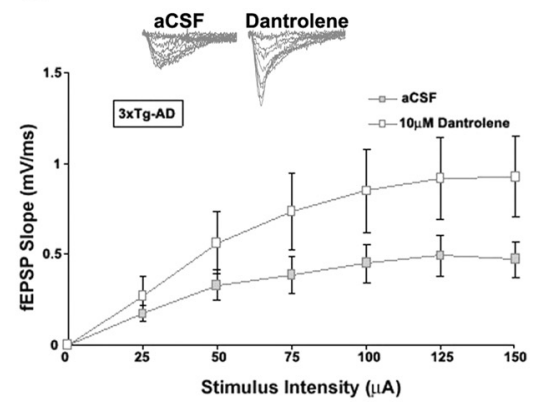

E

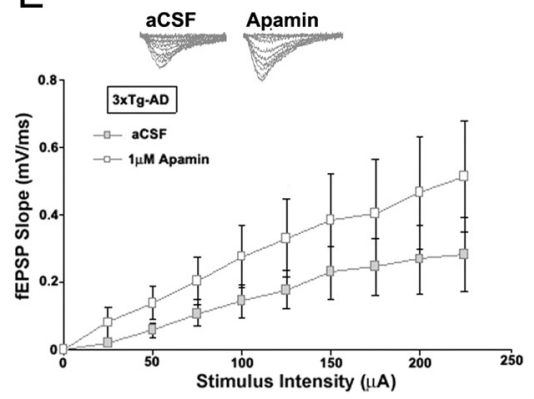

$\mathrm{H}$

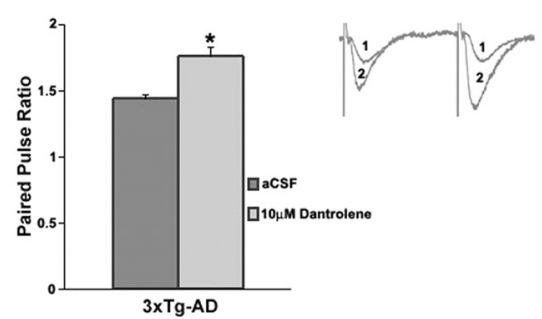

C

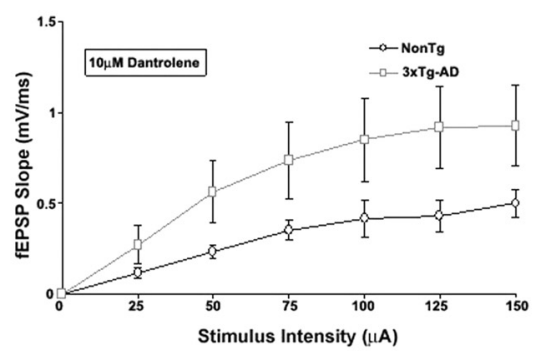

F

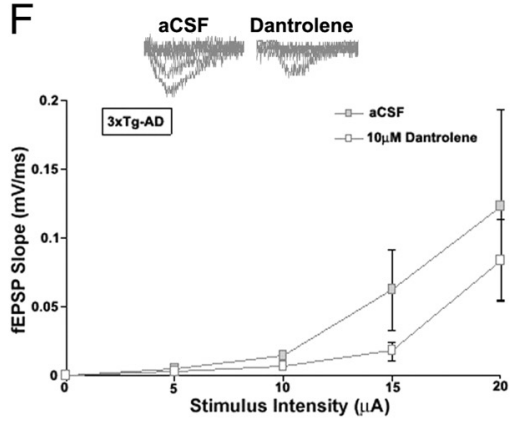

I

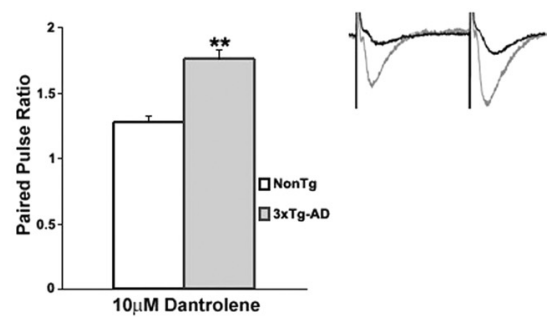

Figure 4. Disparity in the contribution of RyR-mediated ER $\mathrm{Ca}^{2+}$ stores to synaptic transmission in NonTg and 3xTg-AD mice. $\boldsymbol{A}-\boldsymbol{F}$, Top, Representative I/0 traces show changes in fEPSP amplitude with increasing stimulus intensity for NonTg mice $(\boldsymbol{A}$, black) and 3xTg-AD mice ( $\boldsymbol{B}$, gray) before and after treatment with $10 \mu \mathrm{m}$ dantrolene, for NonTg mice $(\boldsymbol{D}$, black) and 3xTg-AD mice ( $\boldsymbol{E}$, gray) before and after treatment with $1 \mu \mathrm{m}$ apamin, and for $3 \mathrm{xTg}-\mathrm{AD}$ mice $(\boldsymbol{F}$, gray) before and after treatment with $10 \mu \mathrm{m}$ dantrolene at low stimulus intensity $(0-20 \mu \mathrm{A})$. Bottom, I/O function shows changes in fEPSP slope with increasing stimulus intensity for NonTg mice before $(\boldsymbol{A}$, filled black circles; $n=5)$ and after (open black circles) and for $3 \times \mathrm{xg}$-AD mice before ( $\boldsymbol{B}$, filled gray squares; $n=9$ ) and after (open gray squares), and comparing NonTg $(\boldsymbol{C})$ (open black circles) and $3 \times \mathrm{Tg}$-AD (open gray squares) mice after treatment with $10 \mu \mathrm{m}$ dantrolene, for NonTg mice before (filled black circles; $n=3$ ) and after (open black circles) $(\boldsymbol{D})$, and 3xTg-AD mice before (filled gray squares; $n=4)$ and after (open gray squares) (E) treatment with $1 \mu \mathrm{m}$ apamin. $\boldsymbol{F}, \mathrm{I} / 0$ function shows changes in fEPSP slope at low stimulus intensity $(0-20 \mu \mathrm{A})$ for $3 \mathrm{xTg}$-AD mice before (filled gray squares; $n=3)$ and after (open gray squares) treatment with $10 \mu \mathrm{m}$ dantrolene. $\mathbf{G}-\mathbf{I}$, PPF was measured at an interstimulus interval of $50 \mathrm{~ms}$. Top, Representative PPF traces from NonTg (G, black) and 3xTg-AD $(\boldsymbol{H}$, gray) mice before (1) and after (2) and comparing NonTg (black) and 3xTg-AD (gray) mice ( $\boldsymbol{I}$ ) after treatment with $10 \mu \mathrm{m}$ dantrolene. Bottom, Bar graphs show paired pulse ratio for $\operatorname{NonTg}(n=5)(\boldsymbol{G})$ and 3xTg-AD $(n=9)(\boldsymbol{H})$ before (black and dark gray, respectively) and after (white and light gray, respectively), and comparing NonTg (white) and 3xTg-AD (light gray) mice after treatment with $10 \mu \mathrm{m}$ dantrolene $(I) .{ }^{*}$ indicates significantly different from $3 \times \mathrm{xTg}$-AD before dantrolene treatment. ${ }^{* *}$ indicates significantly different from NonTg. Error bars represent \pm SEM, $p<0.05$, and $n$ denotes the number of slices.

\section{Divergent synaptic responses to stimulus intensity with RyR blockade in 3xTg-AD mice}

In $3 \mathrm{xTg}-\mathrm{AD}$ mice, the dantrolene-mediated reduction in baseline fEPSP (as measured before the LTP tetanus) (Fig. 5A) is consistent with the observed increase in PPF (indicative of decreased synaptic strength). However, this finding appears in conflict with the increased I/O function during dantrolene application, especially at higher stimulus intensities. To address this disparity, we recorded fEPSPs in control aCSF using a higher stimulus intensity (75 $\mu \mathrm{A}$ rather than $\sim 20 \mu \mathrm{A}$ ), followed by recordings in dantrolene $(10 \mu \mathrm{M})$ at the same stimulus intensity (Fig. 6). The $75 \mu \mathrm{A}$ stimulation was chosen because it evoked near-maximal fEPSP slope responses. Here, too, dantrolene did not change the baseline fEPSP slope in NonTg mice $(2.84 \pm 1.9 \%$ over aCSF baseline; $\left.n=4 ; t_{(1,3)}=0.97 ; p>0.05\right)$. However, in 3xTg-AD mice, dan- trolene still increased the fEPSP slope at this stimulus intensity $\left(163.45 \pm 5.1 \%\right.$ over baseline in aCSF; $n=5 ; t_{(1,4)}=37.95 ; p<$ 0.05). The effects of dantrolene on PPF using the $75 \mu \mathrm{A}$ stimulus intensity were also examined, and there were no significant differences in the $\operatorname{NonTg}\left(n=4 ; t_{(1,3)}=1.34 ; p>0.05\right)$ or 3xTg-AD $\left(n=4 ; t_{(1,3)}=0.86 ; p>0.05\right)$ mice. To further clarify the disparity between the excitatory and inhibitory role of RyR on synaptic transmission, we next examined the effect of dantrolene on basal synaptic transmission using low stimulus intensities $(0-20 \mu \mathrm{A})$ (Fig. $4 F$ ). Dantrolene decreased I/O responses at low stimulus intensities when compared with responses in aCSF in $3 \times \mathrm{xTg}-\mathrm{AD}$ mice $\left(t_{(1,2)}=1.96 ; p>0.05\right)$. These findings suggest activitydependent variations in RyR-mediated calcium signaling in presynaptic and postsynaptic neurons of 3xTg-AD mice that are not present in NonTg mice. 
Effects of RyR stimulation on basal synaptic transmission and short-term presynaptic plasticity

Basal synaptic transmission and synaptic strength were measured by $\mathrm{I} / \mathrm{O}$ curves as described (stimulus intensity, 0-225 $\mu \mathrm{A}$ in increments of $25 \mu \mathrm{A}$ ) and then repeated in the presence of the RyR agonist caffeine (Fig. 7). In addition to stimulating the RyR, caffeine is also an effective antagonist of the adenosine $A_{1}$ receptor that is found in the CA1 hippocampal subfield (Ochiishi et al., 1999; Stutzmann et al., 2001). Caffeine (5 mM) significantly increased the I/O function for the NonTg $\left(n=5 ; t_{(1,4)}=4.96 ; p<0.05\right)$ and $3 x \operatorname{Tg}-\mathrm{AD}\left(n=6 ; t_{(1,5)}=5.14 ; p<0.05\right)$ mice, with no significant difference between the two mouse strains in caffeine $(p>0.05)$. Caffeine did not affect the excitability properties of presynaptic fibers in NonTg or 3xTg-AD mice (FV amplitude vs fEPSP slope: one-way ANOVA, $\left.F_{(1,9)}=2 ; p>0.05\right)$ (data not shown). Caffeine decreased PPF in NonTg $(n=5)$ as well as in $3 \mathrm{xTg}-\mathrm{AD}$ mice $(n=9)$, although to a greater extent in the $3 \times \mathrm{Tg}-\mathrm{AD}$ mice (PPF: one-way ANOVA, $F_{(3,13)}=$ 22.52; $p<0.05$, Scheffé's post hoc analysis, $p<0.05$ for NonTg/caffeine vs NonTg/ aCSF and 3xTg-aCSF; $p<0.05$ for $3 \mathrm{xTg}-\mathrm{AD} /$ caffeine vs NonTg/aCSF and 3xTg-AD/aCSF).

\section{Effects of RyR stimulation on long-term plasticity}

Here we performed the more extensive LTP protocol by recording baseline responses in control aCSF and also in the presence of caffeine ( $5 \mathrm{~mm}$ ) and then administering the tetanus and measuring plasticity in caffeine. As with the dantrolene studies, this allowed us to compare the LTP expression against both a control baseline and a drug baseline (Fig. 8).

There was a substantial increase in baseline fEPSP slopes after caffeine treatment in both NonTg $(n=4 ; 312.51 \pm 5.3 \%$ over aCSF baseline; $\left.t_{(1,3)}=67.39 ; p<0.05\right)$ and $3 x \operatorname{xg}-\mathrm{AD}(n=4$; $337.23 \pm 7.9 \%$ over aCSF baseline; $\left.t_{(1,3)}=43.34 ; p<0.05\right)$ mice. In NonTg mice after caffeine exposure, LTP was increased when compared with its control aCSF baseline $(415.32 \pm 9.7 \%)$ but essentially abolished when compared with the caffeine baseline $(20.25 \pm 0.9 \%)$. This finding is consistent with depletion of neurotransmitter stores in NonTg mice. To further explore this mechanism, we repeated this experiment in caffeine after reducing the stimulus intensity to return the fEPSP amplitude to control levels. Under these conditions, there was a transient expression of LTP 20-30 min after tetanus (106.99 $\pm 6.8 \%$ over caffeine baseline) that returned to pretetanus baseline levels by $50-60 \min (24.29 \pm 7.3 \%$ over caffeine baseline). However, in the $3 \times$ Tg-AD mice, caffeine generated different patterns of LTP expression. LTP was greatly increased when compared with its control aCSF baseline $(800.84 \pm 20.3 \%)$, and considerable potentiation remained when compared with its caffeine baseline $(143.07 \pm 3.2 \%$ over baseline). To ensure that caffeine was not altering baseline responses, we also monitored the long-term effects of caffeine and measured baseline synaptic responses at 0.05

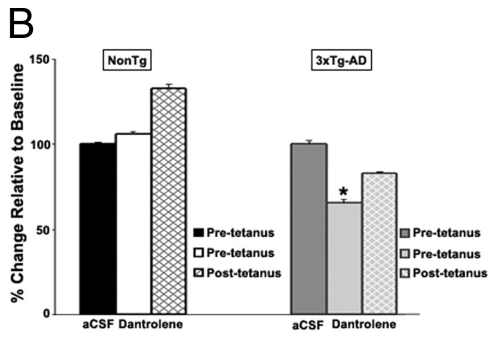

Time (minutes)
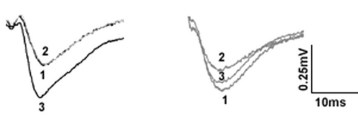

$10 \mu M$ Dantrolen

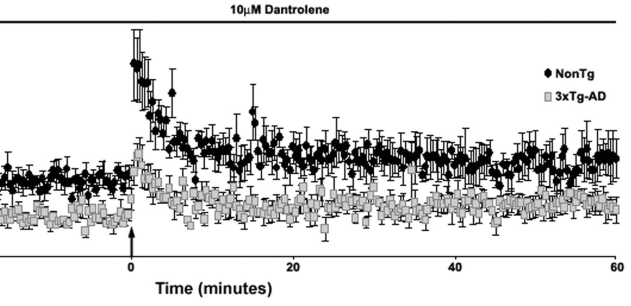

Time (minutes) baseline fEPSP slope from NonTg (black circles; $n=7$ ) and 3xTg-AD (gray squares; $n=5$ ) mice after treatment with $10 \mu \mathrm{m}$ dantrolene. $\boldsymbol{B}$, Bar graph shows fEPSP slope of pretetanus (white and light gray, respectively) and posttetanus (black and gray

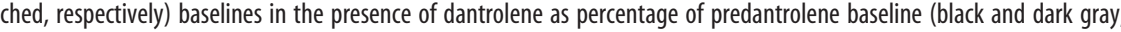
(black circles) and 3xTg-AD (gray squares) mice. The black arrow indicates the time of tetanus. * indicates significantly different Error bars represent \pm SEM, $p<0.05$, and $n$ denotes the number of slices.

$\mathrm{Hz}$ for $60 \mathrm{~min}$ in $5 \mathrm{~mm}$ caffeine (supplemental Fig. 2C, $D$, available at www.jneurosci.org as supplemental material). Long-term caffeine application results in a stable response over time in both the NonTg $\left(233.43 \pm 7.63 \%\right.$ over aCSF baseline; $t_{(1,3)}=28.51$; $p<0.05)$ and the $3 x T g-A D(226.45 \pm 6.4 \%$ over aCSF baseline; $\left.t_{(1,3)}=38.57 ; p<0.05\right)$ mice. These results suggest that RyRmediated calcium stores contribute differentially to synaptic plasticity in NonTg and 3xTg-AD mice.

Because caffeine also blocks the inhibitory presynaptic $A_{1} R$, we examined synaptic properties in the presence of DPCPX, a selective $A_{1} R$ antagonist to distinguish between $A_{1} R$ effects and RyR effects (Fig. 9). DPCPX resulted in a significant and similar increase in the $\mathrm{I} / \mathrm{O}$ function for both the NonTg $\left(n=7 ; t_{(1,6)}=4.62 ; p<0.05\right)$ and 3xTg-AD $(n=4$; $\left.t_{(1,3)}=6.19 ; p<0.05\right)$ mice. DPCPX did not change excitability properties of presynaptic fibers in NonTg or 3xTg-AD mice (FV amplitude vs fEPSP slope: one-way ANOVA, $F_{(1,6)}=2.3$ for NonTg and $F_{(1,3)}=3.6$ for 3xTg-AD; $p>0.05$ ) (data not shown). DPCPX also did not significantly change PPF properties in NonTg $(n=8)$ or in $3 \times \mathrm{xg}-\mathrm{AD}(n=9)$ mice (one-way ANOVA, $\left.F_{(3,16)}=1.16 ; p>0.05\right)$. Treatment with DPCPX similarly increased the baseline fEPSP slope in both NonTg $\left(n=4 ; 71.47 \pm 3.6 \%\right.$ over aCSF baseline; $t_{(1,3)}=16.89 ; p<$ $0.05)$ and $3 \times \mathrm{Tg}-\mathrm{AD}(n=4 ; 84.26 \pm 3.6 \%$ over aCSF baseline; $\left.t_{(1,3)}=21.68 ; p<0.05\right)$ mice. $\mathrm{A}_{1} \mathrm{R}$ antagonism resulted in comparable expression of LTP when compared with control aCSF baseline $(248.88 \pm 5.3 \%$ for NonTg and $235.69 \pm$ $6.1 \%$ for $\left.3 \times \mathrm{Tg}-\mathrm{AD} ; t_{(1,6)}=2.25 ; p>0.05\right)$ and baseline in DPCPX $(176.64 \pm 4.1 \%$ in NonTg and $172.82 \pm 4.7 \%$ in $\left.3 \mathrm{xTg}-\mathrm{AD} ; t_{(1,6)}=1.71 ; p>0.05\right)$ in both NonTg and $3 \mathrm{xTg}-\mathrm{AD}$ mice. 
A
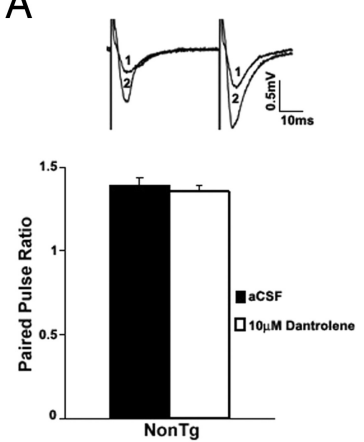

B
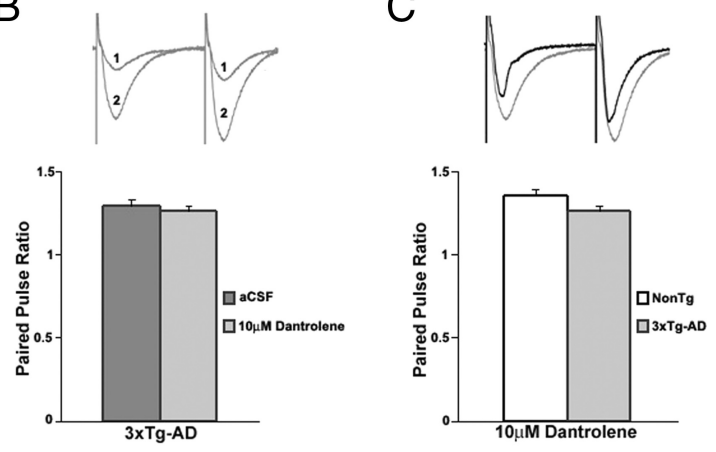

D

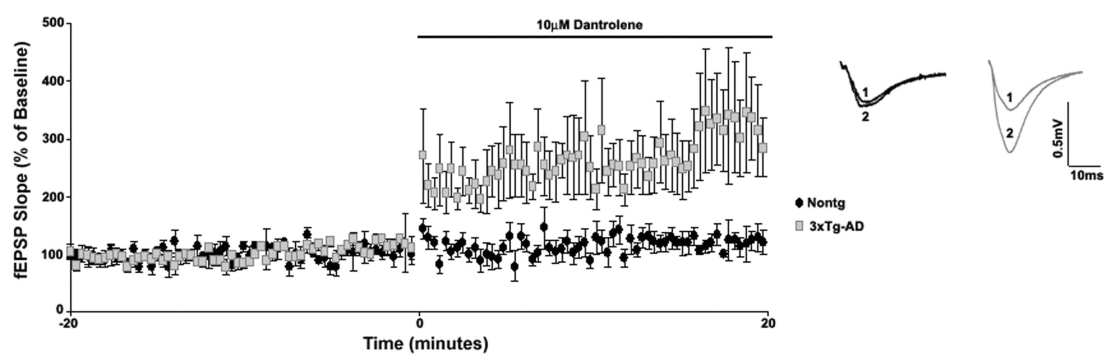

Figure 6. Strong synaptic stimulation differentially recruits $\mathrm{RyR}_{\mathrm{R}-\mathrm{Ca}}{ }^{2+}$ stores in an activity-dependent manner in 3xTg-AD mice. $A-C$, PPF was measured at an interstimulus interval of $50 \mathrm{~ms}$ at a stimulus intensity of $75 \mu \mathrm{A}$. Thisstimulus intensity evoked maximal fEPSP slope responses. The fEPSP slope responses evoked at higher stimulus intensities were not significantly greater than those at $75 \mu \mathrm{A}$. Top, Representative PPF traces from NonTg ( $A$, black) and 3xTg-AD ( $B$, gray) mice before (1) and after (2) and comparing NonTg (black) and 3xTg-AD (gray) mice after treatment with $10 \mu \mathrm{m}$ dantrolene (C). Bottom, Bar graphs show paired pulse ratio for NonTg $(n=4)(A)$ and 3xTg-AD $(n=4)(B)$ mice before (black and dark gray, respectively) and after (white and light gray, respectively) and comparing NonTg (white) and 3xTg-AD (light gray) mice after treatment with $10 \mu \mathrm{m}$ dantrolene (C). D, Left, Graph shows changes in baseline fEPSP slope from NonTg (black circles; $n=4$ ) and 3XTg-AD (gray squares; $n=5$ ) mice after treatment with $10 \mu$ m dantrolene at a stimulus intensity of $75 \mu \mathrm{A}$. Right, Representative fEPSP traces from NonTg (black) and 3xTg-AD (gray) mice before (1) and after (2) treatment with dantrolene. Error bars represent \pm SEM, and $n$ denotes number of slices.

To further parse the distinctive functions of the $A_{1} R$ and RyR in the NonTg and 3xTg-AD mice, we compared the effects of caffeine ( $5 \mathrm{mM}$ ) and DPCPX ( $1 \mu \mathrm{M})$ within each mouse group (supplemental Fig. 1, available at www.jneurosci.org as supplemental material). In the NonTg mice, caffeine and DPCPX generated similar responses in the I/O curves $\left(t_{(1,10)}=0.19 ; p>0.05\right)$ and $\operatorname{PPF}\left(t_{(1,10)}=1.96 ; p>0.05\right)$. In $3 \times \mathrm{Tg}$-AD mice, however, there were significant differences between the effects of caffeine and DPCPX on these synaptic functions. The I/O function was decreased by caffeine but not with DPCPX $\left(t_{(1,8)}=2.66 ; p<0.05\right)$. This discrepant effect may be ascribed to increased coupling efficiency between RyR and postsynaptic hyperpolarizing $\mathrm{Ca}^{2+}-$ activated $\mathrm{K}^{+}$(SK) channels (Stutzmann et al., 2006, 2007) resulting in decreased membrane excitability. Furthermore, PPF was decreased to a much greater extent in caffeine than in DPCPX $\left(t_{(1,16)}=9.13 ; p<0.05\right)$, indicating that RyR-mediated ER calcium release plays a prominent role in basal synaptic transmission and presynaptic neurotransmitter release mechanisms in $3 \times \mathrm{Tg}-\mathrm{AD}$ mice but is not a dominant modulator of these mechanisms in the NonTg mice. The increase in baseline and LTP expression was much greater with caffeine than with DPCPX in both $\operatorname{NonTg}\left(t_{(1,6)}=17.12 ; p<0.05\right)$ and 3xTg-AD $\left(t_{(1,6)}=\right.$ $17.39 ; p<0.05)$ mice. The greater increase in baseline and LTP with caffeine could reflect an additive effect of RyR activation as well as $\mathrm{A}_{1} \mathrm{R}$ inhibition and is consistent with increased probability of neurotransmitter release as indicated by decreased PPF with caffeine.

\section{Discussion}

Mutant PS1-expressing neurons generate markedly enhanced ER calcium responses from young mice (Stutzmann et al., 2004, 2006), yet existing studies show that synaptic physiology and plasticity appear normal until later $\mathrm{A} \beta$ deposition (Oddo et al., 2003; Volianskis et al., 2008). These observations are inconsistent with the tk; 4known calcium requirements for electrochemical neurotransmission. Tight regulation of calcium signaling is a fundamental component of synaptic transmission, modulating both presynaptic and postsynaptic activity as well as complex processes such as plasticity (Nakamura et al., 2000; Lisman, 2003, Bardo et al., 2006). The ER calcium stores are intimately involved in these events while also modifying other calcium sources (Nishiyama et al., 2000; Bardo et al., 2006). For example, LTP at the CA3-CA1 synapse is initiated by calcium entry through the NMDA receptor, yet total calcium is amplified by calcium-induced calcium release) between and within the $\mathrm{IP}_{3} \mathrm{R}$ and RyR channels (Bliss and Collingridge, 1993; Malenka and Bear, 2004). Given the profound ER calcium alterations in 3xTg-AD mice at young ages, we hypothesize that synaptic transmission and plasticity alterations are occurring but are masked by compensatory mechanisms. We observed seemingly normal synaptic transmission in the young $3 \times \mathrm{Tg}-\mathrm{AD}$ mice, yet, on additional investigation, striking differences involving RyR-sensitive calcium stores become apparent. RyR-evoked calcium release may not play a significant role in basal synaptic transmission in NonTg mice, yet this calcium source aberrantly modifies both presynaptic and postsynaptic transmission in 3xTg-AD mice.

\section{Subcellular patterns of RyR-evoked calcium release}

The contribution of ER calcium to synaptic transmission varies according to the subcellular localization of RyR and $\mathrm{IP}_{3} \mathrm{R}$ channels. In CA1 pyramidal neurons, the soma and dendritic shafts express both RyRs and $\mathrm{IP}_{3} \mathrm{Rs}$, whereas distal processes and spine heads express a greater proportion of the RyR (Fitzjohn and Collingridge, 2002; Hertle and Yeckel, 2007; van de Vrede et al., 2007). Thus, the RyR is well positioned for modulating incoming synaptic activity.

Before this study, ER calcium release within 3xTg-AD spine heads had yet to be measured and could have been normal, despite demonstrated differences in the soma and proximal dendrites (Stutzmann et al., 2006, 2007). This could account for the apparent similarity between the NonTg and 3xTg-AD synaptic functions. Here we demonstrate that RyR activation results in significant calcium increases within spines and distal dendrites as well as the soma in $3 \mathrm{xTg}-\mathrm{AD}$ mice. The ER extends into $\sim 50 \%$ of spine heads, and there can modify synaptic signaling through increased glutamate receptor trafficking, CaMKII activation, modification of spine head geometry, and altering signal integration between neighboring spines (Spacek and Harris, 1997; Mat- 
A
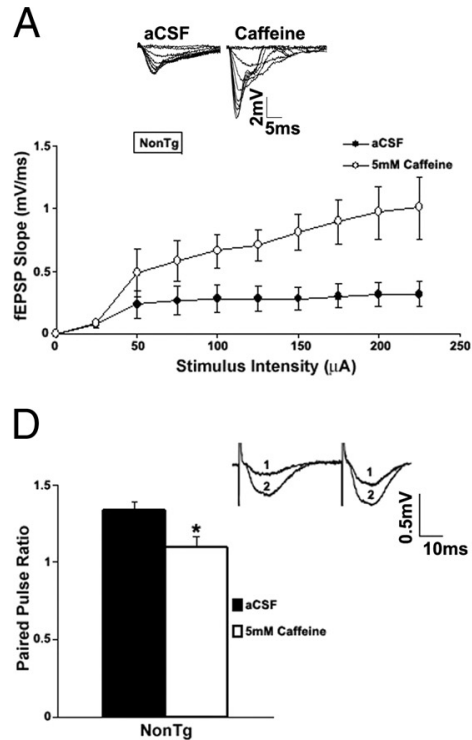

B

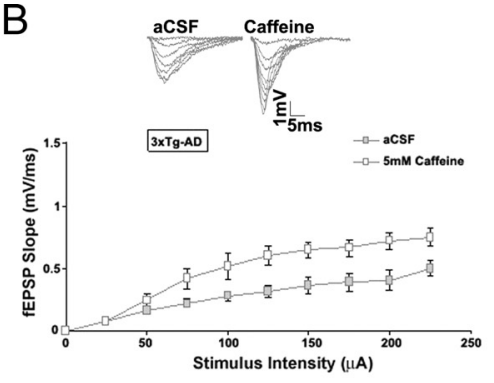

E

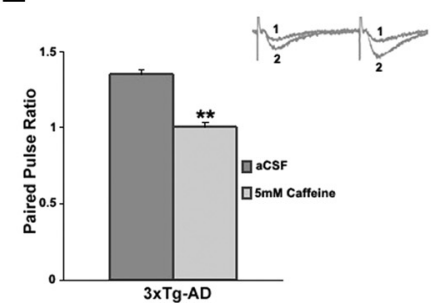

C

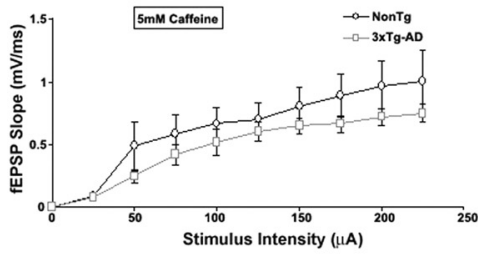

$\mathrm{F}$

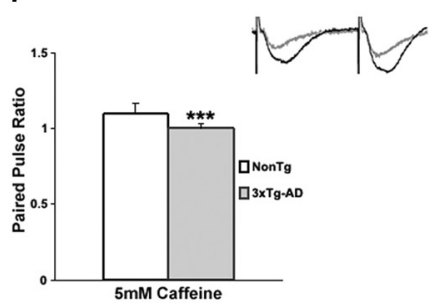

Figure 7. Effect of activating RyR-mediated ER $\mathrm{Ca}^{2+}$ stores on synaptic transmission in NonTg and $3 \times \mathrm{XTg}-\mathrm{AD}$ mice. $\boldsymbol{A}-\boldsymbol{C}$, Top, Representative $\mathrm{I} / 0$ traces show changes in fEPSP amplitude with increasing stimulus intensity for NonTg mice $(\boldsymbol{A}$, black) and for $3 \times \mathrm{Tg}$ - $\mathrm{AD}$ mice $(\boldsymbol{B}$, gray) before and after treatment with $5 \mathrm{~mm}$ caffeine. Bottom, $1 / 0$ function shows changes in fEPSP slope with increasing stimulus intensity $(0-225 \mu \mathrm{A})$ for NonTg mice before $(A)$ (filled black circles; $n=5$ ) and after (open black circles), for $3 \times \mathrm{xTg}$-AD mice before (filled gray squares; $n=$ 6) and after (open gray squares) (B), and comparing NonTg (open black circles) and 3xTg-AD (open gray squares) mice after treatment with $5 \mathrm{~mm}$ caffeine (C). D-F, PPF was measured at an interstimulus interval of $50 \mathrm{~ms}$. Top, Representative PPF traces from NonTg ( $\boldsymbol{D}$, black) and 3xTg-AD ( $\boldsymbol{E}$, gray) mice before (1) and after (2) and comparing NonTg (black) and $3 \times \mathrm{xTg}-\mathrm{AD}$ (gray) mice after treatment with $5 \mathrm{~mm}$ caffeine $(\boldsymbol{F})$. Bottom, Bar graphs show paired pulse ratio for NonTg $(n=5)(\boldsymbol{D})$ and $3 \times \mathrm{Tg}-\mathrm{AD}(n=9)(\boldsymbol{E})$ mice before (black and dark gray, respectively) and after (white and light gray, respectively) and comparing NonTg (white) and 3xTg-AD (light gray) mice after treatment with $5 \mathrm{~mm}$ caffeine $(\boldsymbol{F}) .{ }^{*}$ indicates significantly different from NonTg before caffeine treatment. ${ }^{* *}$ indicates significantly different from $3 \times$ Tg-AD before caffeine treatment. ${ }^{* * *}$ indicates significantly different from NonTg. Error bars represent \pm SEM, $p<0.05$, and $n$ denotes the number of slices.

suzaki et al., 2004; Korkotian and Segal, 2007; Jones et al., 2008). Thus, the enhanced RyR-mediated calcium release in synapsedense regions of 3xTg-AD CA1 neurons may exert distinct modulatory effects on synaptic signals that are not present in the NonTg neurons.

\section{Selective increase in RyR2 mRNA expression in 3xTg-AD hippocampus}

We had shown previously that the $3 \times \mathrm{Tg}-\mathrm{AD}$ mice have increased RyR protein expression levels in whole-brain extracts relative to age-matched NonTg mice (Stutzmann et al., 2006). Here, we further investigated the three RyR isoforms using quantitative PCR methods and found marked increases in the RyR2 isoform in the 3xTg-AD hippocampus (more than fivefold), with relatively little differences in the RyR1 and RyR3 isoforms. In adult rats, all three RyR isoforms are found in the hippocampus, albeit at relatively different levels (Hertle and Yeckel, 2007). Among them, RyR2 is most heavily expressed in the hippocampus (Mori et al., 2000), and, interestingly, selective RyR2 knockdown has been shown to impair hippocampaldependent learning and memory (Galeotti et al., 2008). In the $3 \times \mathrm{Tg}-\mathrm{AD}$ mice, the RyR2 upregulation could primarily account for the increased ER calcium release within the hippocampus, although the mechanism for the specific RyR2 increase is unknown.

\section{Uncovering a deviant synaptic signaling role of ER calcium in} 3xTg-AD mice: presynaptic and postsynaptic effects

In NonTg mice, blocking the RyR produced no changes in PPF, which suggests little RyR-mediated calcium involvement in presynaptic vesicle release. However, in the $3 \mathrm{xTg}-\mathrm{AD}$ mice, dantrolene increased PPF, suggesting an inhibitory effect of presynaptic RyR-evoked calcium release. Likewise, dantrolene did not affect the I/O function in NonTg mice yet significantly increased the I/O function in the 3xTg-AD mice, particularly at higher stimulation intensities. This is consistent with RyRevoked calcium release activating postsynaptic calciumactivated SK channels (Stutzmann et al., 2006; Brennan et al., 2008). In parallel with the effects of dantrolene, blocking the SK channel had little effect on the I/O function in NonTg mice yet increased the I/O function in the $3 \times \mathrm{Tg}-\mathrm{AD}$ mice at higher stimulus intensities.

Stimulating the RyR with caffeine generated different yet complementary patterns. Caffeine, in addition to activating the RyR, also blocks the inhibitory $\mathrm{A}_{1} \mathrm{R}$ and thereby increases neurotransmitter release via presynaptic disinhibition (Martín and Buño, 2003; Gundlfinger et al., 2007; Wang, 2007). Consistent with this, caffeine decreased PPF in both mouse strains, although the decrement was significantly greater in $3 \mathrm{xTg}-\mathrm{AD}$ mice. This may reflect the effects of caffeine on the presynaptic $A_{1} R$ in both mouse strains but with additional RyR recruitment in the 3xTg-AD neurons. To dissociate $A_{1} R$ effects from RyR effects, we used the $A_{1} R$ antagonist (DPCPX) and found similar responses between NonTg and 3xTg-AD neurons. The spontaneous EPSP data also suggest that RyR-mediated calcium release influences both presynaptic and postsynaptic events in the $3 \mathrm{xTg}-\mathrm{AD}$ mice yet has a significantly smaller role in NonTg mice. RyR activation increases both the frequency and amplitude of spontaneous EPSPs in the $3 \times \mathrm{TT}-\mathrm{AD}$ mice only, consistent with presynaptic and postsynaptic effects, respectively.

\section{Differences in ER calcium contribution to LTP}

In NonTg mice, the baseline evoked fEPSP was not significantly affected by dantrolene, which is consistent with the patterns of synaptic activity measured by PPF and I/O functions. Interestingly, the $3 \mathrm{xTg}-\mathrm{AD}$ neurons exhibit a decrease in the dantrolene baseline compared with the aCSF baseline, 
A

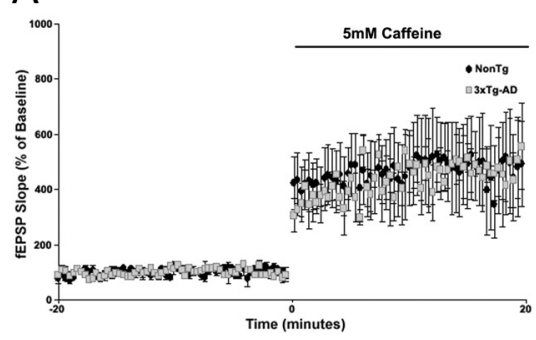

B
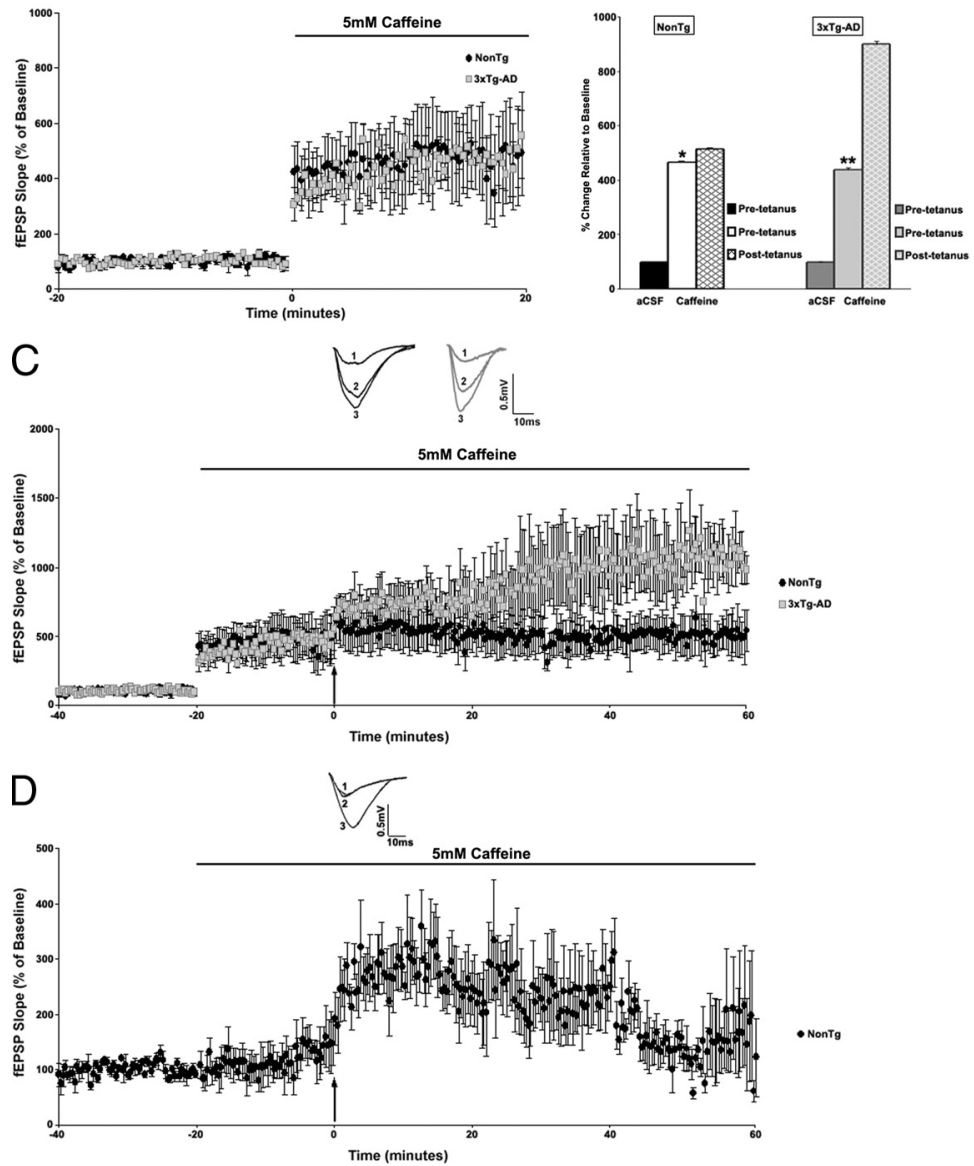

Figure 8. Effect of activating RyR-mediated ER $\mathrm{Ca}^{2+}$ stores on LTP in NonTg and 3xTg-AD mice. A, Graph shows changes in baseline fEPSP slope from NonTg (black circles; $n=4$ ) and 3xTg-AD (gray squares; $n=4$ ) mice after treatment with 5 mm caffeine. $\boldsymbol{B}$, Bar graph shows fEPSP slope of pretetanus (white and light gray, respectively) and posttetanus (black and gray hatched, respectively) baselines in presence of caffeine as percentage of precaffeine baseline (black and dark gray, respectively) in NonTg and 3xTg-AD mice. C, Top, Representative pretetanus fEPSP traces before (1) and after (2) treatment with caffeine and posttetanus fEPSP traces (3) with caffeine from NonTg (black) and 3xTg-AD (gray) mice. Bottom, Graph shows averaged time course of LTP with predrug baseline and pretetanic and posttetanic baseline with caffeine treatment from NonTg (black circles) and 3xTg-AD (gray squares) mice. D, Top, Representative pretetanus fEPSP traces before (1) and after (2) treatment with caffeine and posttetanus fEPSP traces (3) with caffeine from NonTg mice (black). Bottom, Graph shows averaged time course of LTP with predrug baseline and pretetanic and posttetanic baseline with caffeine treatment from NonTg mice (black circles; $n=4$ ). Here, the stimulus intensity was adjusted so that the fEPSP size after caffeine treatment matched the precaffeine fEPSP size. The tetanus was applied at the readjusted stimulus intensity. The black arrow indicates the time of tetanus. ${ }^{*}$ indicates significantly different from NonTg before caffeine treatment. ${ }^{*}$ indicates significantly different from $3 \times \mathrm{Tg}$-AD before caffeine treatment. Error bars represent $\pm \mathrm{SEM}, p<0.05$, and $n$ denotes the number of slices.

presumably attributable to decreased presynaptic neurotransmitter release. This demonstrates opposing roles of RyRmediated calcium release between the NonTg and 3xTg-AD mice. When using the dantrolene baseline as a reference for degree of plasticity, LTP decreased in the NonTg and 3xTg-AD mice, consistent with existing literature (Obenaus et al., 1989; Alford et al., 1993; Emptage et al., 1999). However, these measurements reflect an fEPSP baseline affected by drug application, so we additionally calculated LTP magnitude using the true control baseline. Now, marked differences between the mouse lines arise. When comparing against control fEPSP baseline, there is a modest reduction in LTP expression in the NonTg mice when RyRs are blocked, yet there is a shift from LTP to LTD in the $3 \mathrm{xTg}$-AD mice. Basal synaptic transmission properties are differentially regulated by RyR between the
NonTg and 3xTg-AD mice; therefore, subsequent interpretation of plasticity mechanisms relative to drug baselines will also need to be considered differently.

With caffeine, both NonTg and 3xTg-AD mice exhibited a striking increase in drug fEPSP baseline over predrug fEPSP baseline, which likely reflects increased neurotransmitter release via $A_{1} R$ antagonism. Using the caffeine baseline, there was no additional LTP increase in the NonTg mice, possibly resulting from depletion of presynaptic neurotransmitter pools. By reducing the stimulus intensity to return the fEPSP amplitude in caffeine back to original baseline levels, the likelihood of depletion becomes more evident. Here, short-term potentiation is seen but long-term effects are not sustained. In contrast, the $3 \times \mathrm{Tg}$-AD mice generated considerably greater LTP in caffeine, demonstrating a large reserve for LTP enhancement. These distinctions exposed by RyR manipulation further demonstrate opposing contributions of RyR-sensitive calcium release to plasticity expression between the NonTg and 3xTg-AD mice.

\section{Differential responses to high and low stimulus intensities reflect distinct presynaptic and postsynaptic RyR effects in 3xTg-AD mice}

In the 3xTg-AD mice, RyR blockade appears to exert conflicting effects on synaptic transmission. Dantrolene reduced the baseline field potential slope recorded before the LTP tetanus yet increased the slope of the $\mathrm{I} / \mathrm{O}$ functions and increased the PPF ratio. These discrepancies can likely be explained by stimulus strength differences differentially affecting presynaptic and postsynaptic functions. For LTP baseline and PPF recordings, relatively low stimulus intensities $(\sim 20-25 \mu \mathrm{A})$ were used. PPF is inversely correlated to presynaptic calcium entry, so when blocking RyR-calcium release in the terminal, vesicle release/synaptic strength decreases and PPF increases. This is consistent with the decreased pre-LTP baseline measurements in dantrolene. However, with the higher stimulus intensities used in the $\mathrm{I} / \mathrm{O}$ functions, the postsynaptic recruitment of inhibitory RyR-activated SK channels overcomes the presynaptic effects. The coupling or efficiency between RyR-mediated calcium release and the SK channel is significantly greater in the $3 \mathrm{xTg}-\mathrm{AD}$ mice, such that the same ER calcium response generates a larger outward current in the $3 x \mathrm{Tg}-\mathrm{AD}$ neurons than in NonTg neurons (Stutzmann et al., 2006, 2007). At higher stimulus intensities, blocking this inhibitory influence therefore results in a greater evoked field potential response. In support of these observations, apamin, 
A
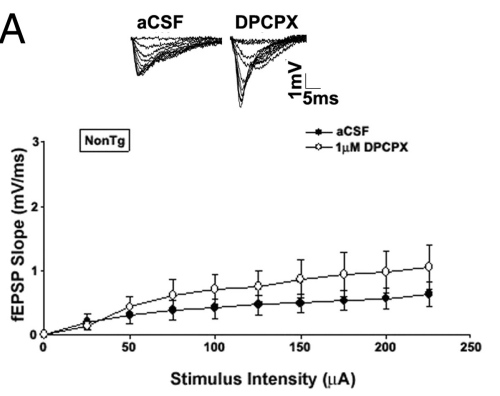

D

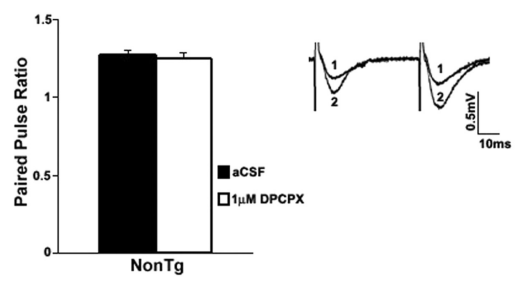

B

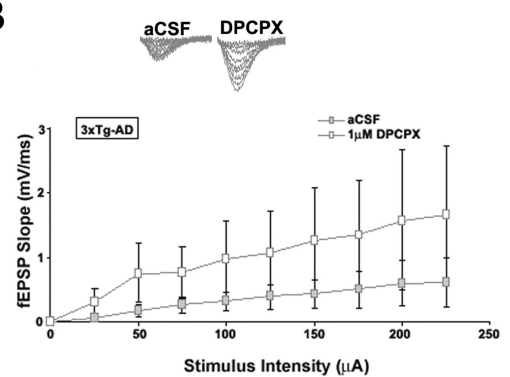

E

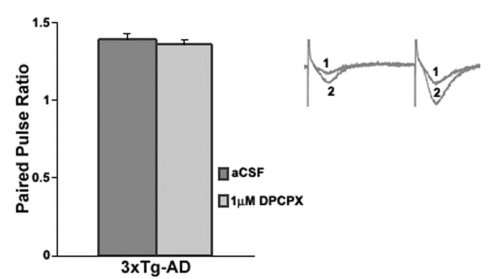

C

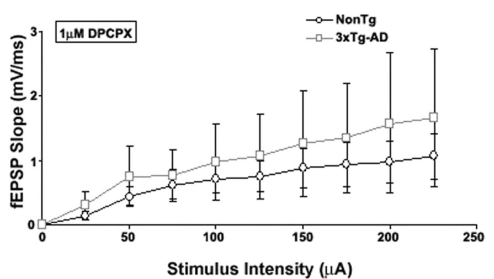

F

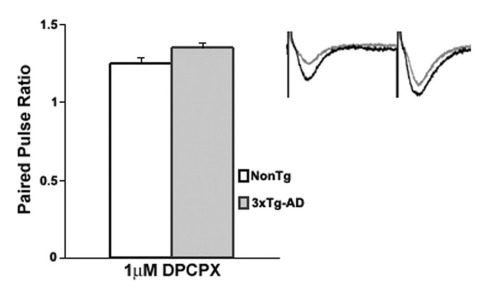

G

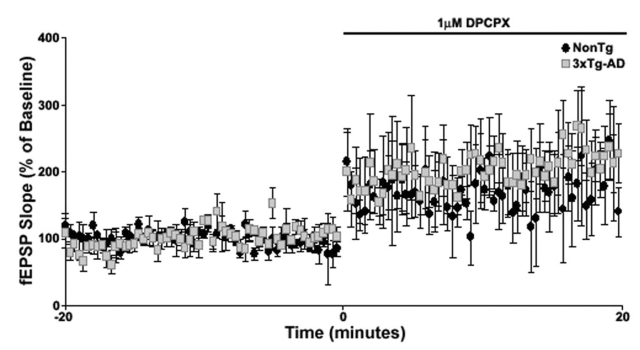

$\mathrm{H}$

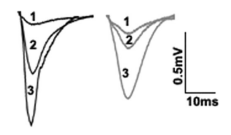

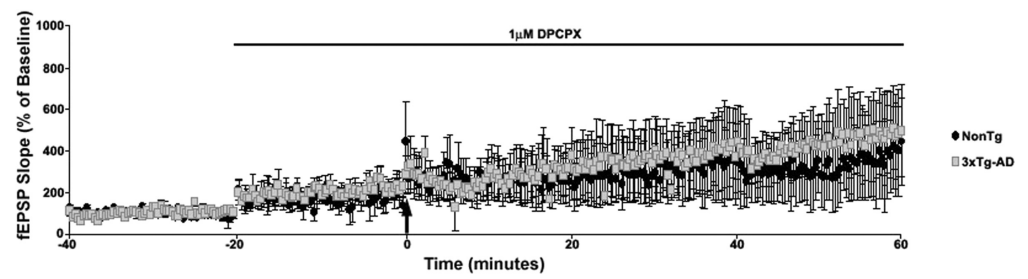

Figure 9. Adenosine $A_{1}$ receptors contribute comparably to synaptic transmission and plasticity in NonTg and $3 x T g-A D$ mice. $A-C$, Top, Representative $1 / 0$ traces show changes in fEPSP amplitude with increasing stimulus intensity for NonTg mice $(\boldsymbol{A}$, black) and for $3 \mathrm{xTg}-\mathrm{AD}$ mice $(\boldsymbol{B}$, gray) before and after treatment with $1 \mu \mathrm{M}$ DPCPX. Bottom, I/0 function shows changes in fEPSP slope with increasing stimulus intensity $(0-225 \mu \mathrm{A})$ for NonTg mice before (filled black circles; $n=7)$ and after (open black circles) $(\boldsymbol{A})$, for $3 \times \mathrm{Tg}$-AD mice before (filled gray squares; $n=4)$ and after (open gray squares) $(\boldsymbol{B})$, and comparing NonTg (open black circles) and 3xTg-AD (open gray squares) mice after treatment with $1 \mu \mathrm{m}$ DPCPX (C). D-F, PPF was measured at an interstimulus interval of $50 \mathrm{~ms}$. Top, Representative PPF traces from NonTg (D, black) and 3xTg-AD (E, gray) mice before (1) and after (2) and comparing NonTg (black) and 3xTg-AD (gray) mice after treatment with $1 \mu \mathrm{M} \mathrm{DPCPX}(\boldsymbol{F})$. Bottom, Bar graphs show paired pulse ratio for NonTg $(n=8)(\boldsymbol{D})$ and $3 \times \operatorname{Tg}-\operatorname{AD}(n=9)(\boldsymbol{E})$ mice before $(\mathrm{black}$ and dark gray, respectively) and after (white and light gray, respectively) and comparing NonTg (white) and 3xTg-AD (light gray) mice after treatment with $1 \mu \mathrm{M}$ DPCPX (F). G, Graph shows changes in baseline fEPSP slope from NonTg (black circles; $n=4$ ) and 3xTg-AD (gray squares; $n=4$ ) mice after treatment with $1 \mu \mathrm{M}$ DPCPX. $\boldsymbol{H}$, Top, Representative pretetanus fEPSP traces before (1) and after (2) treatment with DPCPX and posttetanus fEPSP traces (3) with DPCPX from NonTg (black) and 3xTg-AD (gray) mice. Bottom, Graph shows averaged time course of LTP with predrug baseline and pretetanic and posttetanic baseline with DPCPX treatment from NonTg (black circles) and 3xTg-AD (gray squares) mice. The black arrow indicates the time of tetanus. Error bars represent \pm SEM, $p>0.05$, and $n$ denotes the number of slices.

which selectively blocks the SK channel, increased the I/O functions in the 3xTg-AD mice but had no effect in the NonTg mice.

The dissociation between high and low stimulus intensity effects in the $3 \mathrm{xTg}-\mathrm{AD}$ mice was further verified by repeating the LTP baseline and PPF protocols using higher stimulus intensities that generated near-maximal fEPSPs. There was a significant increase in the fEPSP slope with dantrolene and no change in the PPF, demonstrating a net inhibitory postsynaptic effect of RyR-evoked calcium release on synaptic function. In addition, the excitatory effects of dantrolene seen at higher stimulus intensities are reversed at low and threshold stimulus intensities; here, dantrolene suppresses fEPSPs.

Despite the profound differences in ER calcium release in distal dendrites and spine heads, synaptic function does not appear disrupted in the young 3xTg-AD mice. This suggests that neurons are maintaining a "normal" state, but, in actuality, compensatory mechanisms are likely being recruited to maintain homeostasis. In summary, there are subtle yet profound calcium-mediated alterations in young $3 \times \mathrm{Tg}-\mathrm{AD}$ mice that affect synaptic transmission and plasticity mechanisms in the short term and may contribute to more extensive pathology in synaptic function and cognitive deficits in the later stages of AD.

\section{References}

Alford S, Frenguelli BG, Schofield JG, Collingridge GL (1993) Characterization of $\mathrm{Ca}^{2+}$ signals induced in hippocampal CA1 neurons by the synaptic activation of NMDA receptors. J Physiol 469:693-716.

Bardo S, Cavazzini MG, Emptage N (2006) The role of endoplasmic reticulum calcium stores in the plasticity of central neurons. Trends Pharmacol Sci 27:78-84.

Berridge MJ (1998) Neuronal calcium signaling. Neuron 21:13-26.

Bliss TV, Collingridge GL (1993) A synaptic model of memory: LTP in the hippocampus. Nature 361:31-39.

Bouchard R, Pattarini R, Geiger JD (2003) Presence and functional significance of presynaptic ryanodine receptors. Prog Neurobiol 69:391-418.

Brennan AR, Dolinsky B, Vu MA, Stanley M, Yeckel MF, Arnsten AF (2008) Blockade of $\mathrm{IP}_{3}$-mediated SK channel signaling in the rat medial prefrontal cortex improves spatial working memory. Learn Mem 15:93-96. 
Carter AG, Vogt KE, Foster KA, Regehr WG (2002) Assessing the role of calcium-induced calcium release in short-term presynaptic plasticity at excitatory central synapses. J Neurosci 22:21-28.

Cheung KH, Shineman D, Müller M, Cárdenas C, Mei L, Yang J, Tomita T, Iwatsubo T, Lee VM, Foskett JK (2008) Mechanism of $\mathrm{Ca}^{2+}$ disruption in Alzheimer's disease by presenilin regulation of InsP3 receptor channel gating. Neuron 58:871-883.

Emptage N, Bliss TV, Fine A (1999) Single synaptic events evoke NMDA receptor-mediated release of calcium from internal stores in hippocampal dendritic spines. Neuron 22:115-124.

Fitzjohn SM, Collingridge GL (2002) Calcium stores and synaptic plasticity. Cell Calcium 32:405-411.

Galeotti N, Quattrone A, Vivoli E, Norcini M, Bartolini A, Ghelardini C (2008) Different involvement of type 1,2, and 3 ryanodine receptors in memory processes. Learn Mem 15:315-323.

Gundlfinger A, Bischofberger J, Johenning FW, Torvinen M, Schmitz D, Breustedt J (2007) Adenosine modulates transmission at the hippocampal mossy fiber synapse via direct inhibition of presynaptic calcium channels. J Physiol 582:263-277.

Guo Q, Furukawa K, Sopher BL, Pham DG, Xie J, Robinson N, Martin GM, Mattson MP (1996) Alzheimer's PS-1 mutation perturbs calcium homeostasis and sensitizes PC12 cells to death induced by amyloid betapeptide. Neuroreport 8:379-383.

Hagenston AM, Fitzpatrick JS, Yeckel MF (2008) mGluR-mediated calcium waves that invade the soma regulate firing in layer $\mathrm{V}$ medial prefrontal cortical pyramidal neurons. Cereb Cortex 18:407-423.

Hertle DN, Yeckel MF (2007) Distribution of inositol-1, 4, 5-trisphosphate receptor isotypes and ryanodine receptor isotypes during maturation of the rat hippocampus. Neuroscience 150:625-638.

Ito E, Oka K, Etcheberrigaray R, Nelson TJ, McPhie DL, Tofel-Grehl B, Gibson GE, Alkon DL (1994) Internal $\mathrm{Ca}^{2+}$ mobilization is altered in fibroblasts from patients with Alzheimer's disease. Proc Natl Acad Sci U S A 91:534-538.

Jones VC, McKeown L, Verkhratsky A, Jones OT (2008) LV-pIN-KDEL: a novel lentiviral vector demonstrates the morphology, dynamics and continuity of the endoplasmic reticulum in live neurons. BMC Neurosci 9:10.

Korkotian E, Segal M (2007) Morphological constraints on calcium dependent glutamate receptor trafficking into individual dendritic spine. Cell Calcium 42:41-57.

LaFerla FM (2002) Calcium dyshomeostasis and intracellular signaling in Alzheimer's disease. Nat Rev Neurosci 3:862-872.

Leissring MA, Paul BA, Parker I, Cotman CW, LaFerla FM (1999) Alzheimer's presenilin-1 mutation potentiates inositol 1,4,5trisphosphate-mediated calcium signaling in Xenopus oocytes. J Neurochem 72:1061-1068.

Lisman J (2003) Long-term potentiation: outstanding questions and attempted synthesis. Philos Trans R Soc Lond B Biol Sci 358:829-842.

Malenka RC, Bear MF (2004) LTP and LTD: an embarrassment of riches. Neuron 44:5-21.

Martín ED, Buño W (2003) Caffeine-mediated presynaptic long-term potentiation in hippocampal CA1 pyramidal neurons. J Neurophysiol 89:3029-3038.

Matsuzaki M, Honkura N, Ellis-Davies GC, Kasai H (2004) Structural basis of long-term potentiation in single dendritic spines. Nature 429:761-766.

Mattson MP, Chan SL (2003) Neuronal and glial calcium signaling in Alzheimer's disease. Cell Calcium 34:385-397.

Megías M, Emri Z, Freund TF, Gulyás AI (2001) Total number and distribution of inhibitory and excitatory synapses on hippocampal CA1 pyramidal cells. Neuroscience 102:527-540.

Mellström B, Naranjo JR (2001) Mechanisms of $\mathrm{Ca}^{2+}$-dependent transcription. Curr Opin Neurobiol 11:312-319.

Mori F, Fukaya M, Abe H, Wakabayashi K, Watanabe M (2000) Developmental changes in expression of the three ryanodine receptor mRNAs in the mouse brain. Neurosci Lett 285:57-60.

Nakamura T, Nakamura K, Lasser-Ross N, Barbara JG, Sandler VM, Ross WN (2000) Inositol 1,4,5-trisphosphate $\left(\mathrm{IP}_{3}\right)$-mediated $\mathrm{Ca}^{2+}$ release evoked by metabotropic agonists and backpropagating action potentials in hippocampal CA1 pyramidal neurons. J Neurosci 20:8365-8376.
Nelson O, Tu H, Lei T, Bentahir M, de Strooper B, Bezprozvanny I (2007) Familial Alzheimer's disease-linked mutations specifically disrupt $\mathrm{Ca}^{2+}$ leak function of presenilin 1. J Clin Invest 117:1230-1239.

Nishiyama M, Hong K, Mikoshiba K, Poo MM, Kato K (2000) Calcium stores regulate the polarity and input specificity of synaptic modification. Nature 408:584-588.

Obenaus A, Mody I, Baimbridge KG (1989) Dantrolene-Na (Dantrium) blocks induction of long-term potentiation in hippocampal slices. Neurosci Lett 98:172-178.

Ochiishi T, Chen L, Yukawa A, Saitoh Y, Sekino Y, Arai T, Nakata H, Miyamoto H (1999) Cellular localization of adenosine A1 receptors in rat forebrain: Immunohistochemical analysis using adenosine A1 receptor-specific monoclonal antibody. J Comp Neurol 411:301-316.

Oddo S, Caccamo A, Shepherd JD, Murphy MP, Golde TE, Kayed R, Metherate R, Mattson MP, Akbari Y, LaFerla FM (2003) Triple-transgenic model of Alzheimer's disease with plaques and tangles: intracellular $\mathrm{A} \beta$ and synaptic dysfunction. Neuron 39:409-421.

Park CS, Elgersma Y, Grant SG, Morrison JH (2008) Alpha-isoform of calcium-calmodulin-dependent protein kinase II and postsynaptic density protein 95 differentially regulate synaptic expression of NR2A- and NR2B-containing N-methyl-d-aspartate receptors in hippocampus. Neuroscience 151:43-55.

Park MK, Choi YM, Kang YK, Petersen OH (2008) The endoplasmic reticulum as an integrator of multiple dendritic events. Neuroscientist 14: $68-77$.

Ross WN, Nakamura T, Watanabe S, Larkum M, Lasser-Ross N (2005) Synaptically activated $\mathrm{Ca}^{2+}$ release from internal stores in CNS neurons. Cell Mol Neurobiol 25:283-295.

Rowan MJ, Klyubin I, Cullen WK, Anwyl R (2003) Synaptic plasticity in animal models of early Alzheimer's disease. Philos Trans R Soc Lond B Biol Sci 358:821-828.

Rybalchenko V, Hwang SY, Rybalchenko N, Koulen P (2008) The cytosolic $\mathrm{N}$-terminus of presenilin-1 potentiates mouse ryanodine receptor single channel activity. Int J Biochem Cell Biol 40:84-97.

Selkoe DJ (2008) Soluble oligomers of the amyloid beta-protein impair synaptic plasticity and behavior. Behav Brain Res 192:106-113.

Shankar GM, Li S, Mehta TH, Garcia-Munoz A, Shepardson NE, Smith I, Brett FM, Farrell MA, Rowan MJ, Lemere CA, Regan CM, Walsh DM, Sabatini BL, Selkoe DJ (2008) Amyloid-beta protein dimers isolated directly from Alzheimer's brains impair synaptic plasticity and memory. Nat Med 14:837-842.

Shelbourne P, Coote E, Dadak S, Cobb SR (2007) Normal electrical properties of hippocampal neurons modeling early Huntington disease pathogenesis. Brain Res 1139:226-234.

Smith IF, Hitt B, Green KN, Oddo S, LaFerla FM (2005) Enhanced caffeineinduced $\mathrm{Ca}^{2+}$ release in the $3 \times \mathrm{Tg}-\mathrm{AD}$ mouse model of Alzheimer's disease. J Neurochem 94:1711-1718.

Spacek J, Harris KM (1997) Three dimensional organization of smooth endoplasmic reticulum in hippocampal CA1 dendrites and dendritic spines of immature and mature rat. J Neurosci 17:190-203.

Stutzmann GE (2007) The pathogenesis of Alzheimer's disease is it a lifelong "calciumopathy"? Neuroscientist 13:546-559.

Stutzmann GE, Marek GJ, Aghajanian GK (2001) Adenosine preferentially suppresses serotonin ${ }_{2 \mathrm{~A}}$-receptor enhanced EPSC's in layer $\mathrm{V}$ neurons of the medial prefrontal cortex. Neuroscience 105:55-69.

Stutzmann GE, LaFerla FM, Parker I (2003) $\mathrm{Ca}^{2+}$ signaling in mouse cortical neurons studied by two-photon imaging and photoreleased inositol triphosphate. J Neurosci 23:758-765.

Stutzmann GE, Caccamo A, LaFerla FM, Parker I (2004) Dysregulated IP 3 signaling in cortical neurons of knock-in mice expressing an Alzheimer'slinked mutation in presenilin1 results in exaggerated $\mathrm{Ca}^{2+}$ signals and altered membrane excitability. J Neurosci 24:508-513.

Stutzmann GE, Smith I, Caccamo A, Oddo S, Laferla FM, Parker I (2006) Enhanced ryanodine receptor recruitment contributes to $\mathrm{Ca}^{2+}$ disruptions in young, adult, and aged Alzheimer's disease mice. J Neurosci 26:5180-5189.

Stutzmann GE, Smith I, Caccamo A, Oddo S, Parker I, Laferla FM (2007) Enhanced ryanodine-mediated calcium release in mutant PS1-expressing Alzheimer's mouse models. Ann N Y Acad Sci 1097:265-277.

Townsend M, Shankar GM, Mehta T, Walsh DM, Selkoe DJ (2006) Effects 
of secreted oligomers of amyloid \{beta\}-protein on hippocampal synaptic plasticity: a potent role for trimers. J Physiol 572:477-492.

Tu H, Nelson O, Bezprozvanny A, Wang Z, Lee SF, Hao YH, Serneels L, De Strooper B, Yu G, Bezprozvanny I (2006) Presenilins form ER Ca ${ }^{2+}$ leak channels, a function disrupted by familial Alzheimer's disease-linked mutations. Cell 126:981-993.

van de Vrede Y, Fossier P, Baux G, Joels M, Chameau P (2007) Control of IsAHP in mouse hippocampus CA1 pyramidal neurons by RyR3-mediated calcium-induced calcium release. Pflugers Arch 455:297-308.

Verkhratsky A (2002) The endoplasmic reticulum and neuronal calcium signaling. Cell Calcium 32:393-404.

Volianskis A, Kostner R, Molgaard M, Hass S, Jensen MS (2008) Episodic memory deficits are not related to altered glutamatergic synaptic transmission and plasticity in the CA1 hippocampus of the APPswe/ PS1DeltaE9-deleted transgenic mice model of beta-amyloidogenesis. Neurobiol Aging. Advance online publication. Retrieved Jan. 10, 2009. doi:10.1016/j.neurobiolaging.2008.08.005.

Wang SJ (2007) Caffeine facilitation of glutamate release from rat cerebral cortex nerve terminals (synaptosomes) through activation protein kinase C pathway: an interaction with presynaptic adenosine A1 receptors. Synapse 61:401-411.

Watanabe S, Hong M, Lasser-Ross N, Ross WN (2006) Modulation of calcium wave propagation in the dendrites and to the soma of rat hippocampal pyramidal neurons. J Physiol 575:455-468. 